\title{
Review Article \\ Planar Cell Polarity Pathway in Kidney Development and Function
}

\author{
Brittany Rocque and Elena Torban \\ Department of Medicine and Physiology, McGill University and McGill University Health Center, 3775 University Street, \\ Montreal, QC, Canada H3A $2 B 4$ \\ Correspondence should be addressed to Elena Torban; elena.torban@mcgill.ca
}

Received 17 September 2014; Revised 25 January 2015; Accepted 8 February 2015

Academic Editor: Carlos G. Musso

Copyright (C) 2015 B. Rocque and E. Torban. This is an open access article distributed under the Creative Commons Attribution License, which permits unrestricted use, distribution, and reproduction in any medium, provided the original work is properly cited.

\begin{abstract}
The evolutionarily conserved planar cell polarity (PCP) signaling pathway controls tissue polarity within the plane orthogonal to the apical-basal axis. PCP was originally discovered in Drosophila melanogaster where it is required for the establishment of a uniform pattern of cell structures and appendages. In vertebrates, including mammals, the PCP pathway has been adapted to control various morphogenetic processes that are critical for tissue and organ development. These include convergent extension (crucial for neural tube closure and cochlear duct development) and oriented cell division (needed for tubular elongation), ciliary tilting that enables directional fluid flow, and other processes. Recently, strong evidence has emerged to implicate the PCP pathway in vertebrate kidney development. In this review, we will describe the experimental data revealing the role of PCP signaling in nephrogenesis and kidney disease.
\end{abstract}

\section{General Introduction}

Development of the mammalian kidney is a complex process involving repeated local interactions between progenitor cells of the intermediate mesoderm and branches of the ureteric bud that culminate in the formation of thousands (mouse) or hundreds of thousands (humans) of nephrons (extensively reviewed in $[1,2]$ ). Each nephron consists of phenotypically and functionally distinct segments; an ultrafiltrate of plasma generated by the glomerulus is delivered to the proximal tubule followed by the loop of Henle and distal convoluted tubule, fused to a collecting system derived from the arborized ureteric bud. As it passes along the nephron, tubular fluid is modified by reabsorption of water, key electrolytes, and nutrients while unwanted metabolic waste products are allowed to flow into the collecting system and out to the bladder. Nephrogenesis relies on a differentiation cascade that requires timely changes in cell shape, movement, and alignment that lead to clusters of specialized epithelia lining each segment. Disturbance of these molecular and cellular events manifests in a wide variety of congenital anomalies of kidney and urinary tract in humans [3]. In the past 20-30 years, a great deal has been learned about the physiology of each nephron segment but the molecular events that specify cell fate and align cells along the nephron are poorly understood.

During embryogenesis, the mechanisms that establish cellular polarity are critical for complex organs such as the kidney. Polarization within cells can be thought of as a cell's sense of direction. Apical-basal (AB) polarity is the most thoroughly studied axis of cell polarity. Experiments in Drosophila revealed that the $\mathrm{AB}$ polarity is initially established by reciprocal interactions between three polarity complexes: apical Crumbs and Par complexes with the basal Scribble complex [4-7]. Once appropriate apical and basal membrane domains are established, effector molecules linked to these polarity complexes organize the actin cytoskeleton and vesicular protein transport in a spatially polarized manner. The mechanisms controlling vertebrate $\mathrm{AB}$ polarity are not yet well-defined but a complex network of fruit fly $A B-$ related proteins has been identified which is critical for generation and maintenance of epithelial cell polarity in vertebrates $[8,9]$. Overall, AB polarity is crucial for tissue barrier formation, vectorial transport functions, cell adhesion, cytokinesis, and other cellular events, which are indispensable for the morphogenesis and functions of epithelial tissues. 


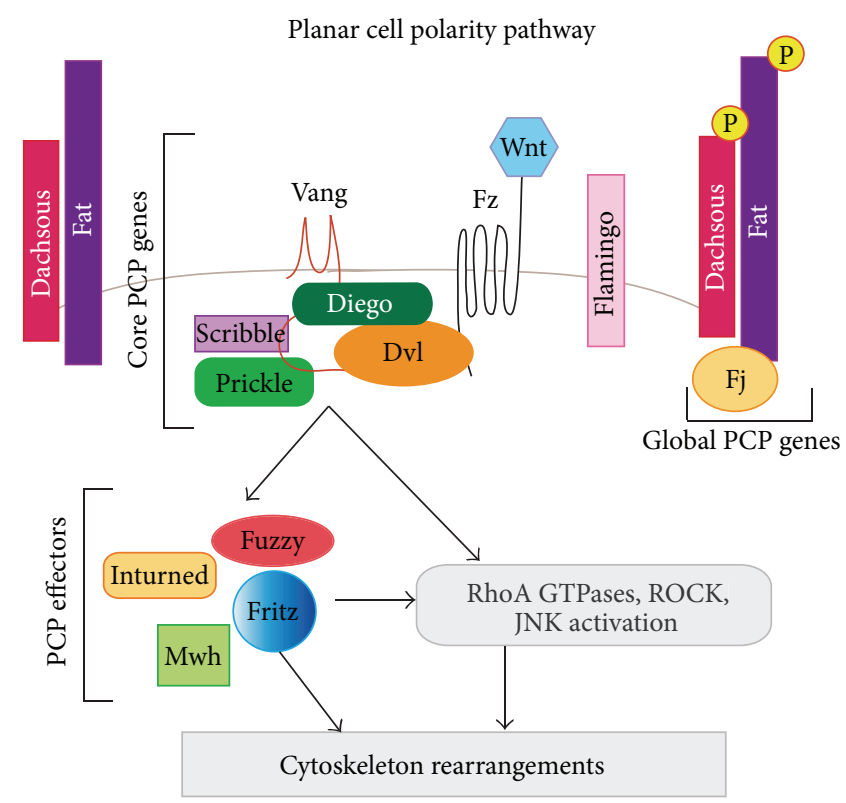

Figure 1: The PCP signaling pathway in Drosophila. The PCP pathway is activated when a Wnt ligand binds to a Frizzled (Fz) receptor and induces a clustering of the core PCP proteins to either proximal (Van Gogh-like (Vangl) and Prickle (Pk)) or distal (Dishevelled (Dvl) and Fz, Diego) cellular domains. Activation of PCP signaling is associated with Dvl phosphorylation. Flamingo (Celsr) is found at both sides. Apicalbasal regulator Scribble also regulates PCP in the fruitflies and genetically interacts with Vangl2. Dachsous (Ds) and Fat (Ft) protocadherins form heterotypic complexes at both sides of the cell and provide global positioning cues; phosphorylation of Ft and Ds by the Four-jointed (Fj) kinase regulates the strength of the Ds-Ft complex. Asymmetric distribution of the core PCP proteins induces asymmetric clustering and activation of downstream PCP effectors Inturned (In), Fuzzy (Fuz), Fritz, and multiple wing hair (Mwh) as well as a Rho GTPase, Jun kinase, and others. This leads to actin rearrangement necessary for polarized asymmetric distribution of cellular appendages.

In addition to $\mathrm{AB}$ polarity, many epithelial tissues display a second axis of polarity along an orthogonal "proximaldistal axis," known as planar cell polarity (PCP) (reviewed in $[10,11])$. In the case of the renal tubule, this would be cell polarity along the path of tubular flow. PCP is observed in both invertebrates, for example, as a uniform orientation of hair on fruit fly wing cells (where it was initially described and studied) [12-14] and vertebrates (e.g., as a uniform orientation of scale on fish) [10]. These patterns are orchestrated by an evolutionarily conserved PCP signaling pathway (Figure 1). In mammals, mutations of PCP pathway components lead to multiple developmental abnormalities including neural tube and cardiac defects and misorientation of hair cells in the cochlea, lung, limb, facial anomalies, and other defects (reviewed in [10]). These congenital abnormalities underscore the critical role for the PCP pathway in organogenesis. A role for PCP genes in nephrogenesis has recently been proposed (reviewed in $[15,16]$ ). In this review, we provide an update on current understanding of how the PCP pathway contributes to kidney development and maintenance of adult renal function. We then discuss how disturbances of the PCP pathway contribute to human kidney disease.

\section{Mammalian Kidney Development}

Mammalian kidneys are derived from the mesodermal germ layer. In mice and humans, a portion of the intermediate mesoderm on either side of the spine is transformed into an epithelial structure, the nephric duct (ND), which extends caudally as a single tube. Development of a permanent "metanephric" kidney in mammals starts at the 5th week of gestation in humans and approximately at day 10.5 of embryonic development (E10.5) in mice when the ureteric bud (UB) grows out from the posterior portion of the ND and invades the metanephric mesenchyme (MM), a column of undifferentiated nephron progenitor cells situated laterally to the posterior ND [1]. Signals from the MM induce repetitive branching of the UB that generates the entire renal collecting system (collecting duct tree, renal pelvis, and ureter) (Figure 2(a)). Cellular events implicated in UB branching include cell migration, oriented cell division, and cytoskeletal rearrangements [17]. Concomitantly, signaling molecules secreted by the UB cause the MM to condense around the UB tips and form organized structures: renal vesicles and comma- and S-shaped bodies that represent successive stages of nephrogenesis [17]. In response to inductive UB signals, nephron progenitor cells around the UB tip (cap mesenchyme) undergo a mesenchyme-to-epithelium transition involving changes in cell adhesion properties and cell polarization along the apical-basal and proximal-distal axes. In mice, the ureteric bud continues to arborize and induce new generations of nephrons into the postnatal period. By postnatal day 14 (P14) nephrogenesis comes to an end and the final complement of $\sim 13,000$ nephrons is fixed for life. In humans, nephrogenesis ends by 38 weeks gestation, yielding a final complement of about 800,000 nephrons/kidney [1]. 


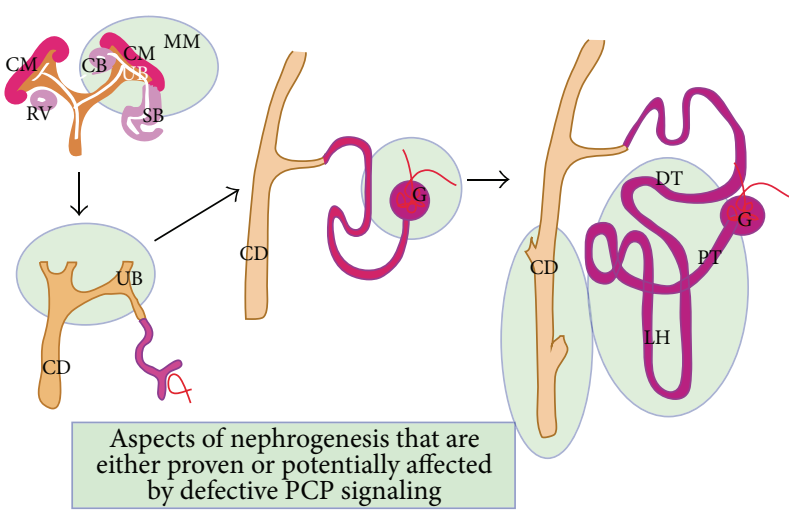

(a)

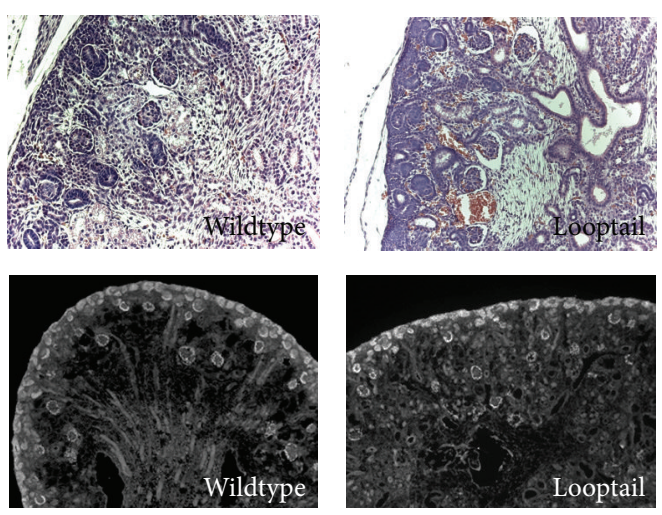

(b)

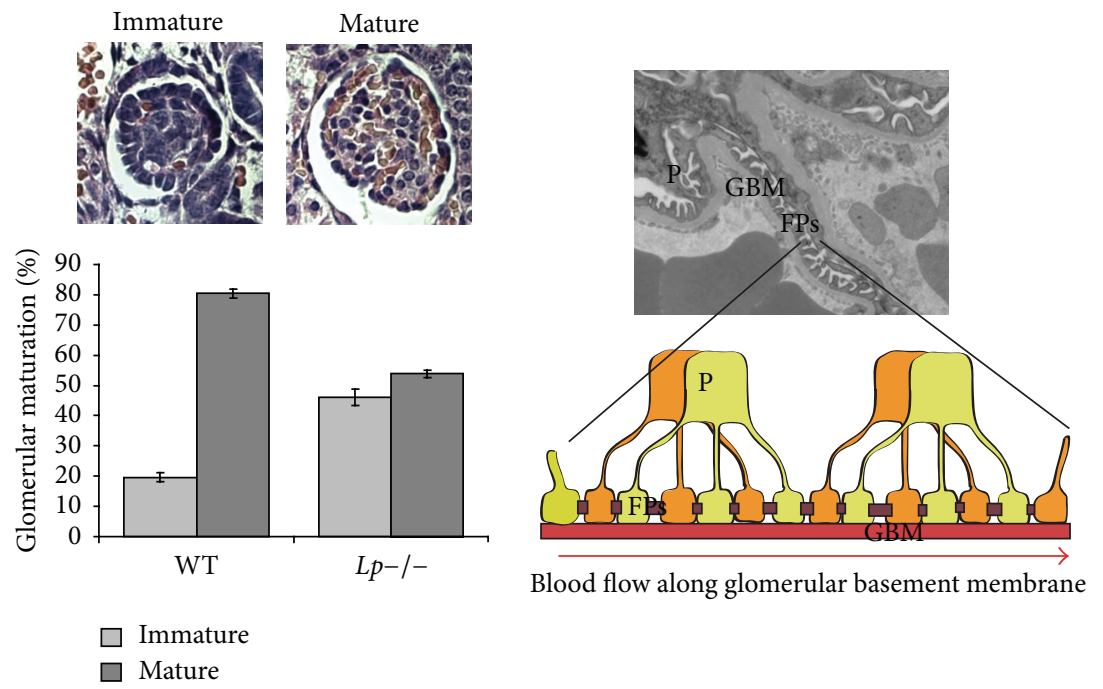

(c)

(d)

FIGURE 2: Normal kidney morphogenesis and kidney defects in Looptail mouse. (a) Stages of kidney development: ureteric bud (UB) invades the metanephric mesenchyme (MM) to induce clustering of the nephron progenitor cells above UB tip (cap mesenchyme, CM) to epithelize sequentially into a renal vesicle (RV), comma-shaped body (CB), and S-shaped body (SB). The SB fuses with an arborizing collecting duct $(\mathrm{CD})$ at the distal end and forms a glomerulus $(\mathrm{G})$ at the proximal end. The SB elongates and differentiates to form proximal tubules (PT), loop of Henle (LH), and distal tubules (DT). The shaded areas designate morphogenetic processes where the PCP pathway may be involved. (b) Upper panels: hematoxylin and eosin-stained E17.5 wildtype (left) and Looptail (right) kidneys, magnification $\times 200$; lower panels: WT1 antibody-immunostained wildtype (left) and $L p$ (right) kidney images, magnification $\times 100$. (c) Upper panels: images of immature (capillaryloop stage) and more mature glomeruli; lower panel: statistical analysis of glomerular developmental delay in $L p$ versus wildtype kidneys. (d) Electron microscopy of mouse glomerulus (left) and a schematic depiction of the podocyte foot processes along GBM (right): podocyte (P), glomerular basement membrane (GBM), and foot processes (FPs). The results of (b) and (c) were partially published in Rocque, 2014, JASN and are published with the permission of JASN.

A complex system of transcription factors and signaling molecules govern UB branching, induction of nephron progenitor cells, the mesenchyme-to-epithelium transition (MET), and terminal differentiation of specific nephron segment cells (excellently reviewed by Costantini [17]). A set of transcription factors (e.g., Six2 and Osrl) define cap mesenchyme-derived progenitor cells which give rise to the majority of nephron segments $[18,19]$. Action of the Wnt/ $\beta$ catenin pathway is crucial for the survival and self-renewal of nephron progenitor cells, MET induction, and UB branching [20-22]. The transcription factor PAX2 is a key regulator of early kidney development. Its loss results in renal agenesis due to failure of ND development and UB outgrowth [23].
Of particular importance to UB arborization are interactions between the receptor tyrosine kinase, Ret, and glial glycophosphatidylinositol-linked coreceptor, GFR $\alpha$, with the glial derived neurotrophic factor, GDNF [17]. Mutations of any of these three genes result in renal agenesis [24-26]. Mutations of transcription factor genes that regulate expression of GDNF (e.g., Eyal or Hox11) or Ret (e.g., Gata3) also cause renal agenesis or hypoplasia [27-29]. In general, failure of any of the early nephrogenic processes manifests in renal anomalies ranging from complete renal agenesis to modest renal hypoplasia/dysplasia with associated ureteral defects, conditions known in humans as Congenital Anomalies of Kidney and Urinary Tract, CAKUT [3]. 
Upon formation of the nephron epithelium, further specification is required to give rise to the specific nephron segments [30,31]. For example, Notch $/ \gamma$-secretase signaling is necessary for development of the proximal tubular and glomerular segments [32-34]. Loss of Notch2 in the MM leads to loss of proximal cell types without affecting the distal nephron epithelium or UB branching [35]. Podocyte precursors are specified at the most proximal part of the Sshaped body and this process relies on the interplay between Pax2 and Wilms-Tumor 1, WT1, genes [36, 37]: initially, Pax2 induces high levels of WT1 expression needed for podocyte specification [38], yet suppression of Pax 2 expression by WT1 is later required to complete podocyte differentiation $[39,40]$. Once podocyte precursors are specified, they undergo extensive metamorphosis (discussed in detail in Section 4.2) [41]. Recently, strong evidence has implicated the planar cell polarity pathway in some aspects of kidney development. These issues are discussed in the sections below.

\section{Planar Cell Polarity Pathway}

3.1. PCP Functions in Drosophila. 40 years ago, Lawrence and Shelton described a uniform ommatidial pattern in the retina of the milkweed bug, Oncopeltus fasciatus, and hypothesized that it might be regulated by an unknown gradient factor(s) [42]. In 1982, Gubb and Garcia-Bellido described planar polarization of hairs on the wing cells of the fruit fly, Drosophila melanogaster, and identified several genetic loci responsible for specific planar arrangements of wing hairs [12]. These pioneering works initiated a new field of research into planar cell polarity (PCP). In Drosophila, many organs display uniform orientation of cellular structures or appendages within the tissue: for example, each cell in the fly wing produces a single hair at the most distal point of the cell (indicative of polarity within an individual cell); all hairs are distally oriented (indicating a global tissue polarity); in the multifaceted Drosophila eye, each of the $\sim 800$ ommatidia is oriented in relation to the eye's midline (reviewed in [10]). This planar polarity pattern relies on PCP genes. There are two main classes of PCP genes. The first includes atypical protocadherins, Fat (Ft) and Dachsous (Ds), and the Golgiassociated kinase Four-jointed (Fj). Ft and Ds are expressed on both sides of each wing cell and form heterodimers which may act as bridges between the two adjacent cells. Ft is equally distributed along the wing blade but expression of Ds and Fj is inversely graded along the tissue: high Ds is expressed at the proximal margin while $\mathrm{Fj}$ accumulates at the distal zone of the wing [43]. The binding affinities between Ft and Ds are regulated by $\mathrm{Fj}$, which phosphorylates both cadherins. As a result, the Ft-Ds complex expression is graded along the tissue and this provides a global polarity cue $[44,45]$. The second class of PCP molecules are encoded by "core" PCP genes: the WNT receptor Frizzled (Fz), transmembrane proteins Van Gogh/Strabismus (Vang/Stbm), and Flamingo/Starry Night (Fmi/Stan) and cytoplasmic proteins Dishevelled (Dsh/Dvl), Prickle (Pk), and Diego (Dg) [46, 47] (Figure 1). Core PCP proteins define the axis of planar polarization in each cell and are sensitive to long-range input from upstream polarity cues [48]. Mutations of the core genes result in PCP defects in all fruit fly tissues studied [10]. In addition to global and core PCP proteins, several planar polarity effector proteins have also been identified including Inturned (In), Fuzzy (Fy), Fritz (Frtz), and multiple wing hair (Mwh). In, Fy, and Frtz act as a discrete genetic and biochemical module to regulate position and number of hair on each wing cell [49]. The apical-basal regulator Scribble (Scrib) interacts genetically and biochemically with Vang/Stbm, Scrb functions as Vang effector exacerbating Vang ommatidia and wing hair planar polarity defects [50]. In some tissues, the proteins of the RhoA family of small GTPases (Rhol and Racl) serve as effectors to regulate actin rearrangements [51-53]. The RhoA regulatory Drosophila Rho-associated kinase (Drok) also acts as a PCP effector: it affects Myosin II and actin cytoskeletal rear rangements [54]. Jun-Kinase (JNK) is activated by PCP signaling to mediate maturation of cytoskeleton dynamics $[52,53,55,56]$. Unlike core PCP genes (needed for PCP in all tissues), specific effector genes are required for the planar polarity in a restricted subset of tissues.

Planar cell polarity is achieved via the asymmetric localization of core PCP protein complexes. Earlier papers suggested that the Ft-Ds-Fj module establishes an axis of polarity across the tissue and this triggers the asymmetric distribution of core PCP molecules in each individual cell [57]. However, this upstream-downstream relationship between the global and core PCP modules has been questioned and alternative model has been proposed in which the two cassettes function in parallel with some cross talk between them $[58,59]$. Recently, Wu et al. showed that an early instructive PCP signal is provided by the two Drosophila Wnt members, Wingless $(\mathrm{Wg})$ and Wnt4, which are expressed in a gradient and act redundantly as Fz ligands [48]. Wg/Wnt4 -Fz binding regulates $\mathrm{Fz}$ activity, which, in turn, provides the planar directional cue and triggers asymmetric relocalization of PCP protein complexes. In the fly wing epithelium, Vang forms a complex with $\mathrm{Pk}$ at the proximal domain of the cell; the Vang/Pk complex excludes the Fz/Dvl complex which demarcates the distal domain of the same cell [60-64]. The asymmetry is sustained by inter- and intracellular mechanisms that collectively generate a negative feedback loop that enhances and sustains asymmetric PCP protein distribution [61, 65, 66]. Wu et al. showed that $\mathrm{Fz}$ (which is localized at the distal part of one cell) binds to an extracellular loop of Vang localized at the proximal side of a neighboring cell; stability of the Fz-Vang intercellular interaction depends on $\mathrm{Wg} / \mathrm{Wnt} 4$ concentration [48]. The Fz-Vang extracellular binding leads to stabilization of both Vang/Pk and Fz/Dvl complexes to the opposite cellular domains [66]. Intracellularly, Pk is degraded by the Smurf ubiquitin ligases at the distal side, whereas, in the complex with Vang, stabilized Pk precludes accumulation of Dvl in the proximal domain [67]. Asymmetry of the core PCP proteins further translates into the asymmetric localization of PCP effectors: for example, the In-Fy-Frtz cassette is detected at the proximal edge of wing cells and controls the distal accumulation of Mwh (a formin-homology containing protein); the latter directly regulates initiation of actin polymerization at the most distal aspect of the wing cell [68]. 
Recently, Classen et al. demonstrated that, in addition to controlling actin rearrangements, PCP signaling was necessary for normal hexagonal packaging of wing cells [69]. In order to achieve hexagonal shape, cells must remodel their intercellular junctions. This process is modulated by PCPmediated endocytosis of E-Cadherin [69]. PCP signaling also regulates E-cadherin turnover and junctional levels during tracheal morphogenesis and this, in turn, promotes cell intercalation and tracheal elongation [70]. Taken together, PCP molecules control several critical cellular processes during fly development, underscoring the general importance of PCP signaling to Drosophila morphogenesis.

3.2. PCP Functions in Vertebrates. Homologs of the Drosophila PCP genes operate in vertebrates [10]. Various Wnt ligands (Wnt5a, Wnt9b, and Wnt11) activate PCP signaling in vertebrates [71-74]. Because Wnt, Frizzled, and Dishevelled molecules are involved (all are the key regulators of the canonical Wnt/ $\beta$-catenin pathway), PCP signaling has historically been also referred to as a "noncanonical" Wnt signaling pathway. Vertebrate genomes contain two vertebrate Vang genes, Van Gogh-like (Vangl) 1 and Vangl2 [75], three Fmi homologous (Celsr1-3), three Dsh homologous genes, Dvl1-3, four vertebrate homologs of Pk, Pk1-4, four homologs of Ft gene, Fat1-4, and two Ds genes, Dachsous1 and Dachsous2. There are single Fuzzy, In, and Fritz vertebrate genes [76-78]. The AB regulator Scribble 1 was implicated in murine PCP [79], and the atypical tyrosine kinase Ptk7 was also shown to regulate mammalian PCP [80]. In mice, the PCP pathway controls the uniform orientation of stereocilia bundles on cochlear hair cells [81] and patterning of hair on the head [82], characteristics reminiscent of hair alignment on fruit fly wings. Additionally, in vertebrates, the PCP pathway has been adapted to morphogenetic processes such as neural tube closure $[75,79,80,83,84]$, development of the cardiac outflow tract [83, 85-87], face and palate structure [88], somite organization [89], lung branching morphogenesis [90], cochlear development [81, 91, 92], and other morphogenetic processes.

The prototypic feature of many mouse PCP gene mutants is a severe neural tube defect, craniorachischisis, which represents complete failure of neural tube closure (extensively reviewed in [93, 94]). Neural tube formation is a complex process which begins with flattening of the neural plate. Subsequent shaping then depends on the morphogenetic process of convergent extension, CE $[95,96]$. CE was first described in developing Xenopus laevis embryos during gastrulation and is a general term for a process whereby cells intercalate to decrease the width of a structure in one direction (convergence) and to increase the length of the structure in the perpendicular axis (extension) [97]. Sokol showed that overexpression of the Xenopus Dvl2 mutant Xdd1 causes neural tube defects, body shortening, and characteristic dorsal flexure of the posterior portion of the embryo [98]. Xdd1 acts as a dominant-negative mutant in the context of Wnt $\beta$ catenin stimulation, yet $\mathrm{Xdd} 1$ does not impact $\mathrm{Wnt} / \beta$ catenin-dependent mesoderm induction and differentiation; Xddl blocks convergent extension movements in dorsal marginal zone tissue, thus affecting the PCP-related process [98]. During gastrulation and neurulation, dorsal mesodermal and neuroepithelial cells extend mediolateral lamellipodia that facilitate directional cell movement toward the midline; injections of Xdd1 mRNA severely disrupt the polarity of these projections, interfering with the axis of cell elongation and ultimately affecting CE $[96,98,99]$. A Vangl2 mutation in the Looptail mouse was shown to affect CE of both mesoderm and neuroepithelium, causing a characteristic "looped" tail in heterozygotes and craniorachischisis in homozygous embryos [100]. CE underlies the morphogenesis of several other organs. For example, elongation of the cochlear duct along the longitudinal axis relies on $\mathrm{CE}$ and is disrupted in many PCP mouse mutants [81, 83].

In 2006, Park et al. observed shorter and sparser cilia in the epidermal multiciliated cells of Xenopus laevis embryos when the PCP effectors Inturned and Fuzzy were knocked down [76]. The phenotype of mice with homozygous knockout of Fuzzy or Inturned is similar to that of mice with mutation of core PCP genes (e.g., looped tail and cardiac outflow defects). However, Fuzzy and Inturned mutants also exhibit anomalies associated with defective cilia (e.g., cranial NTDs, polydactyly, and hydrochephalus). Mice with Fuzzy or Inturned mutations have short primary cilia $[77,78,101,102]$. Core PCP proteins are involved in a variety of ciliary functions; knockdown of Dishevelled in Xenopus reduces cilial number and length and randomizes the position of basal bodies in frog multiciliated skin cells [103]. A compound mouse lacking all three mammalian Dvl homologues (Dvl1/2/3) exhibits similar defects in the position and orientation of basal bodies of motile cilia in ependymal and nodal cells [104, 105]. Homozygous mutations of Celsr 2 and Celsr 3 lead to severe hydrocephalus due to randomization of cerebral spinal fluid flow, due to a loss of uniform planar polarization of cilia in brain ependymal cells [106]. In a set of elegant experiments using ex vivo airway epithelial cell cultures, Vladar et al. showed that a set of PCP proteins contributes to ciliary functions by conveying information from the asymmetric PCP protein complexes at cell junctions to the microtubule and actin networks that define position of ciliary basal bodies [107]. Overall, asymmetric actin rearrangement, convergent extension, and function of cilia are among the crucial cellular processes regulated by PCP signaling during morphogenesis of organs.

\section{Planar Cell Polarity Pathway and Kidney}

Strong recent evidence now points to a role for PCP signaling in nephrogenesis and in maintenance of the adult kidney. For example, abnormally shaped, hypoplastic/dysplastic kidneys were found in homozygous Vangl 2 or Fat 4 mutant mice. This strongly suggests a requirement for PCP signaling during primary morphogenesis of the kidney. Interestingly, planar polarity during elongation of renal tubules (oriented cell division along the tubular plane) appears to be randomized in cystic kidney diseases linked to dysfunction of the primary cilium. Features of the PCP pathway during normal nephrogenesis and in the pathogenesis of renal cysts are discussed in detail below. 
4.1. PCP Pathway and Early Kidney Development. Hypodysplastic, duplicated, and/or misshapen kidneys have been observed in mice with mutations in several PCP genes [108110]. Hence, it is logical to assert that PCP signaling is required during early kidney development. Yun et al. recently showed that the PCP Wnt ligand, Wnt5a, is expressed in a graded manner at the posterior end of the intermediate mesenchyme [111]. Conditional ablation of Wnt5a in the intermediate mesenchyme prior to the UB outgrowth at E7.5 leads to bilateral duplication of ureters and duplex kidneys. Homozygous mutation of the PCP coreceptor, Ror2, also results in an extranumerary kidney phenotype, albeit at low frequency. Combining homozygous Ror2-/-inactivation with a heterozygous Wnt5a allele produces frequent duplex kidneys. Thus, noncanonical Wnt5a/Ror2 signaling is necessary for the earliest nephrogenic events such as patterning of the nephric cord and regulation of the initial UB outgrowth from the ND [111]. Wnt9b acts in both canonical and noncanonical Wnt signaling $[20,74]$. Through its canonical function, Wnt9b regulates progenitor pool size and controls mesenchymeto-epithelial transition that heralds differentiation of early nephron structures [20,112]. As a PCP pathway ligand, Wnt9b is required for tubular elongation via CE [74]. Another PCP Wnt, Wnt1l, is specifically expressed at the tips of each ureteric bud branch (UB). Targeted Wntll excision in the ureteric bud lineage leads to defective branching morphogenesis, precluding normal expression of Ret receptor in UB cells and the Ret ligand, GDNF, in the metanephric mesenchyme [113]. Reduced arborization of the UB ultimately translates into fewer nephrons since each UB tip provides inductive cues for conversion of the adjacent cap mesenchyme into a nephron [113]. The renal phenotype of either Wnt5a or Wnt11 mutant mice is reminiscent of the phenotypes observed in mice with deregulation of canonical Wnt/ $\beta$-catenin pathway: for example, overexpression of $\beta$-catenin in mesonephric mesenchyme results in ND patterning defects, excessive expression of Ret, and extranumerary kidneys [21]; loss of $\beta$ catenin in UB reduces UB branching culminating in severe renal hypoplasia [22]. One possibility is that, during kidney development, Wnt5 and Wnt1l participate in both Wnt/ $\beta$ catenin and PCP signaling. Indeed several Wnt molecules, including Wnt5a, were reported to act in both Wnt pathways [114] but the particular Wnt pathway activation seems to depend on unknown tissue-specific factors [115]. Another possibility is that the activities of the canonical Wnt and the PCP pathways are interdependent. For example, a hypermorphic allele of the canonical Wnt coreceptor lipoprotein receptor-related protein, Lrp6, increased Wnt canonical and, simultaneously, abolished PCP-induced JNK activities [117]. Several proteins have been shown to act as molecular switches between the Wnt/ $\beta$-catenin and PCP signaling pathways [116, $118]$ lending credibility to this mechanism.

Kidneys of Looptail (Lp) E17.5-18.5 embryos are misshapen, smaller, and dysplastic (Figure 2(b)) [108, 109]. We showed that Vangl2 protein is expressed at high levels in the nephric duct and in metanephric epithelium derived from both mesenchymal and UB lineages during the embryonic period [119]. Yates et al. found a substantial defect in branching morphogenesis of E13.5 mutant Vangl2 kidneys: the kidneys were smaller and had $25 \%$ fewer nephrons in homozygous and $\sim 15 \%$ fewer nephrons in heterozygous $L p$ embryos; the proliferation index and apoptosis in wildtype and mutant $L p-/-$ renal tissues were equivalent [109]. Some abnormalities in actin distribution in $\mathrm{Lp}-/$ - cells were also observed, suggesting that actin dysregulation may affect changes in cell shape and/or cell motility needed for proper branching morphogenesis. Additionally, we identified a profound loss of the medullary zone and of tubular bundles in Vangl2 mutants, indicating potential defects in tubular elongation (Figure 2(b)).

Ye et al. described substantial renal hypoplasia (no sign of dysplasia) in targeted combined Fz4-/-; Fz8-/- mutants [120]. Both Fz4 and Fz8 participate in the PCP signaling and are expressed exclusively in UB branches. Their combined loss does not disturb mesenchyme-to-epithelial transition but affects the length of the ureteric bud prior to branching; no defects in cell proliferation or apoptosis were identified. A similar phenotype is seen in Pax2 heterozygotes where heightened apoptosis compromises UB branching and reduces final nephron number [121].

PTK7-/- embryos exhibit hypoplastic kidneys but detailed analysis of these kidneys is lacking [80]. Andreeva et al. recently found that PTK7 controls junctional localization of ROCK2 (a known PCP pathway participant), which is required for apical rearrangement of actomyosin and epithelial morphogenesis [122]. Saburi et al. reported that, in addition to dilated tubules (renal dysplasia), kidneys of Fat4-/mice are also smaller. Of note, double Fat4-/-; Fjx-/mutants produce ectopic ureters and duplicated kidneys at low frequency $[110,123]$; the underlying mechanisms for smaller, extranumerary kidneys in this double mutant have not been elucidated in detail. In summary, deficiency of the PCP pathway leads to various kidneys anomalies which arise from the abnormal early nephrogenesis.

4.2. PCP and Glomerular Development. Podocytes are highly polarized renal glomerular cells that regulate formation of the glomerular ultrafiltrate. Podocytes develop in the proximal cleft of the S-shaped body from precursors that initially appear as typical cuboidal epithelia with tight junctions at the cell apex (reviewed in [41]). As differentiation proceeds, the cell-cell junctions migrate from the apical to the basal aspect of the cell and transform into unique sieve-like junctional complexes that connect adjacent "foot processes" (FPs) extending from neighboring cells. FPs contain precisely organized actomyosin bundles and form a unique alternating pattern such that a FP from one podocyte interacts only with a FP from the adjacent podocyte. Interdigitating FPs are arranged perpendicular to the axis of flow in the underlying capillary. Their slit diaphragms form the only points of contact between adjacent cells leaving the podocyte cell body to project into the urinary space. Mutations in slit diaphragm proteins lead to podocyte detachment and progressive glomerular dysfunction [41].

The role of the PCP pathway has recently been studied in glomerular podocytes. Babayeva et al. showed that components of the PCP pathway Vangl1, Vangl2, Pricklel, Scribble, 
Dishevelled 2, and others are expressed in glomeruli and in cultured human and mouse podocytes [119]. It was further demonstrated that stimulation of cultured human or mouse podocytes with Wnt5a leads to an increase in both the average number of stress fibers and cellular protrusions per cell. Conversely, RNA interference-mediated depletion of Vangl2 in mouse and human podocytes leads to fewer stress fibers and projections per cell, a measure that can be correlated with FP structure in vivo. Loss of Vangl2 in cultured podocytes also results in redistribution of nephrin (a major slit diaphragm adhesion molecule) from the cell surface. In human embryonic kidney HEK293 cells expressing exogenous nephrin, loss of Vangl2 or stimulation with Wnt5a causes nephrin internalization via clathrin/ $\beta$-arrestin-mediated endocytosis [108]. Vangl2 was shown to form a protein complex with nephrin [119].

Yates et al. and our group reported defects of glomerular development in Lp (Vangl2 $\left.{ }^{5464 \mathrm{~N}}\right)$ mice: glomerular development was delayed compared to controls and a small proportion of $L p$ glomeruli exhibited collapsed tufts and signs of degeneration $[108,109]$. Podocyte-specific Cre-LoxPmediated abrogation of Vangl2 resulted in a similar glomerular developmental delay phenotype [124]. However, by the end of nephrogenesis at P14, a developmental "catch-up" seems to have occurred so that the glomeruli in either mutant or control mice looked similar, though mutant glomeruli were smaller and had fewer podocytes. Podocyte-specific loss of Vangl2 did not affect filtration function in adult kidneys: protein excretion at 12 months was comparable in both genotypes [124]. Yet, in the context of glomerular injury induced by heterologous anti-glomerular basement membrane (antiGBM) antibody, the extent of injury was heightened and glomerular recovery was impaired in mutant versus control animals. This effect could not be attributed to the initial podocyte deficit in mutant glomeruli: postinjury loss of podocytes was increased in mutant mice, suggesting that Vangl2 is required for optimal podocyte recovery (e.g., via its effect on actin) and/or adhesion (via its effects on turnover of adhesion molecules). Importantly, anti-GBM injury greatly induced glomerular expression of many PCP transcripts indicating that PCP signaling is important for glomerular recovery after injury.

WT1 specifies podocyte fate and induces expression of Scribble in the developing and mature podocyte [125]; Scribble participates in the mammalian PCP pathway [81]. Hartleben et al. investigated the role of Scribble in the murine glomerulus using both podocyte-specific Cremediated Scribble knockout and the circletail mutant mouse (which expresses a shortened Scribble protein) [126]. In mice, Vangl2 and Scribble produce identical NTD and cochlear phenotypes and interact genetically and biochemically [79, 81]. Similarly, in zebrafish, both proteins act together to regulate neural tube formation [127]. Surprisingly, Hartleben et al. found no evidence that Scribble contributes to glomerular maturation or that it is required for filtration function under normal physiological conditions or after injury in mice [126]. These results suggest that the requirement for certain PCP genes may be tissue-specific. The differences between Vangl2 and Scribble glomerular phenotypes may lie in the fact that the latter is involved in the specification of basal features of apical-basal polarity. In podocytes, it may function in apical-basal polarity but not in polarity along the epithelial plane.

In mice, homozygous loss of Fat1, a giant atypical protocadherin homologous to the Drosophila Ft gene, leads to perinatal death [128]. Some mice also display holoprosencephaly and cyclopia, phenotypes often attributed to abnormal adhesion or defective Sonic Hedgehog signaling [129]. Light microscopic analysis showed no gross morphological abnormalities in Fat1 mutant kidneys; however, electron microscopy revealed a global loss of FPs and complete lack of slit diaphragms. The authors concluded that Fatl acts as an important structural part of the slit diaphragm protein complex; its loss disrupts slit diaphragms and causes fetal congenital nephrotic syndrome [128]. During nephrogenesis, Fat1 is expressed at a high level in developing podocytes [130]. In rats with acute puromycin aminonucleoside nephrosis, expression of Fatl protein increases after injury and concentrates in the new junctional contacts between podocytes that form after FPs are lost. The authors concluded that Fatl may be involved in formation of initial contacts between adjacent podocytes during development and during the recovery phase after acute injury before the mature podocyte architecture is achieved [130].

4.3. PCP, Tubulogenesis, and Cystic Kidney Disease. Cystic kidney disease is a heterogenous group of human disorders characterized by the presence of dilated tubules and/or multiple macrocysts arising from foci along various segments of the renal tubule (extensively reviewed in $[131,132]$ ). Among the many forms of hereditary renal cystic disease, the most common is autosomal-dominant polycystic kidney disease (ADPKD) associated with mutations of the PKD1 or PKD2 genes. Recessive forms of cystic kidney disease are caused by homozygous mutations of PKHD1 (ARPKD) or genes associated with the Meckel-Gruber syndrome-Bardet-Biedl syndrome-nephronophthisis spectrum. The common feature of all mutant genes causing cystic renal disease (including $P K D 1 / 2)$ is that they encode proteins localized to the primary cilium and/or basal body; hence, these disorders are often referred to as ciliopathies (extensively reviewed in [133]). Ciliary membrane is enriched for receptors and channels which sense the extracellular milieu and transduce this information (chemosensation, mechanosensation, cell position along the epithelial tubule, etc.) into intracellular signals [134]. Components of many developmental pathways localize either at the basal body or along the ciliary membrane $[135,136]$. Hence, it is not surprising that abnormalities of ciliary structure or function affect developmental signaling. Members of both Wnt $/ \beta$-catenin and PCP pathways have been localized to the primary cilium [137]. However, the details of how cilia are linked to these two pathways are actively debated [138-140]. For the purpose of our review, we will focus primarily on empiric observations supporting a relationship between PCP proteins and cystic kidney disease and on the relationship of mutant cilia to dysfunctional PCP signaling during renal cyst formation. 
In 2005, Simons et al. reported that inversin (encoded by the NPHP2 gene mutated in humans with nephronophthisis type 2 ) acts as a molecular switch between the noncanonical and canonical Wnt/ $\beta$-catenin signaling pathways during organogenesis [116]; an antagonistic relationship between these two pathways was suggested. Indeed, several recent publications presented convincing data documenting antagonistic relationship between $\mathrm{Wnt} / \beta$-catenin activity and PCP signaling $[117,118]$. The inv/inv mouse has cystic kidneys and laterality defects (situs inversus) [141], and knockdown of inv in zebrafish leads to a shortened anterior-posterior axis and widened somites, a classical manifestation of defective PCP signaling. Inversin contains several ankyrin-repeats and shares significant structural similarities with the Drosophila PCP protein Diego [142]. Like Diego, inversin interacts with PCP proteins Dvl and Vangl2 [116]. Based on the phenotypic features of inv zebrafish morphants, inversin protein structure and binding properties, it has been proposed that defective PCP may contribute to the pathogenesis of cystic kidney disease [116]. Previously, Bellache et al. had shown that intact PCP signaling is required for mitotic spindle orientation in Drosophila neuroblasts [143], and Gong et al. demonstrated that oriented cell division (OCD) was controlled by the PCP pathway in zebrafish [144]. Germino synthesized these observations into an elegant model whereby a cystic phenotype arises as a consequence of defective PCP signaling that disturbs cell division alignment in proliferating tubular cells [145]. According to this model, longitudinally oriented OCDs generate daughter cells that extend the tubule along its longitudinal axis while maintaining a constant tubular diameter [145]. Germino's model predicted that OCD would be lost in tubular cystic cells. In confirmation of this hypothesis, Fischer et al. demonstrated polarized longitudinal alignment of mitotic spindles in 95\% of dividing renal tubular cells in young mice [146]. Importantly, these authors observed randomized orientation of cell divisions in dilated/cystic tubules of mice with inactivation of the Hepatic Nuclear Factor beta$1, H N F \beta 1$, gene ( $H N F \beta 1$ is mutated in patients with diabetes and congenital cystic kidney disease [147]) and in Pck rat with polycystic kidneys [146]. This important work confirmed that the loss of OCD may contribute to cystogenesis. In subsequent years, numerous studies have examined the complex relationship between the PCP pathway, OCD, and cystogenesis [115, 131, 132].

The first experimental evidence implicating the PCP pathway directly in cystogenesis came in 2008 when Saburi et al. showed that loss of Fat4 (a homolog of the Drosophila PCP gene Fat) leads to a cystic kidney phenotype by embryonic day E16.5 [110]. In addition, Fat4 knockout mice display other characteristics of disturbed PCP such as defects of cochlear elongation, mild misorientation of stereociliary bundles within the Organ of Corti, curly tails, shortened body axis, and thickened neural tube; homozygous Fat4-/mice die perinatally. The kidneys of Fat4-/- mice exhibit a loss of elongated collecting ducts and Loop of Henle, yet no change in proliferation or apoptosis of tubular cells was found. The authors detected randomized OCD in the Fat4-/- renal tubules and concluded that the loss of OCD underlies significant tubular dilation and renal cysts [110].
In subsequent work, Saburi et al. demonstrated that Fat4 genetically interacts with vertebrate Fat1 and Fat3 genes [123]. Although homozygous Fatl or Fat3 mutant mice do not display tubular dilation or cysts, combined Fat1-/-; Fat4-/- double mutants have smaller kidneys with increased cystic phenotype compared to Fat4-/- animals. In addition, Fat1-/-; Fat4-/- mutants exhibit exencephaly (a phenotype not seen in mice with homozygous Fat mutations), shorter cochlear ducts, and defects in the alignment of cochlear hair cells [123]. On the other hand, Fat 3 appears to antagonize Fat 4 in the kidney and the combined Fat4-/-; Fat3-/- animals have a smaller cystic area than Fat4-/- pups. Intriguingly, the cystic and cranial NTD phenotype of Fat4-/-; Fat1-/- ani mals is reminiscent of the phenotype in mice and humans with mutations in certain ciliopathy genes (e.g., Mks1) [148, 149]. These observations suggest a potential role for Fat genes in the function of primary cilium. Indeed, Fat 4 protein has been detected at the cilium [110], but its function there remains unknown.

Fat proteins may affect tissue PCP but may also function through the Hippo signaling pathway, which regulates tissue size by controlling cell proliferation, death, and differentiation [150]. This raises the possibility that the renal phenotype of Fat mutants may be due to disruption of the Hippo pathway. Indeed, loss of TAZ, the major downstream effector of Hippo pathway, results in polycystic kidneys [151]. Inappropriate activation of the Hippo pathway was detected in several mouse PKD models [152].

Saburi et al. reported that combining the Fat4-/- mutants with heterozygous mutations of the core PCP gene, Vangl2 (Lp mouse), exacerbates the cystic phenotype [110, 123]. Interestingly, we observed tubular dilation and occasional tubular or glomerular cysts in the E17.5 kidneys of homozygous $L p$ mice that bear a missense S464N mutation in the Vangl2 gene (Figure 2(b)) [108, 109]. Thus, Vangl2 may impact renal tubular development by affecting the primary cilium, OCD, or some other mechanism, but this remains controversial. Borovina et al. found defects in the alignment of ciliary basal bodies but not in the ciliary structure of primary cilia in pronephros and neural tube of the zebrafish Vangl2 mutant trilobite [153]. Similarly, Song et al. reported a disturbance of cilial tilting in the embryonic node of Vangl2-/-; Vangl1-/embryos [154]; Antic et al. showed a loss of uniform cilial tilting in frogs with Vangl2 knockdown [155]. However, MaySimera et al. reported that knockdown of Vangl2 affects ciliary length in zebrafish [156]. Vangl2 protein was detected in the cilium of nasal epithelial cells [157] and we visualized a GFP-tagged Vangl2 protein in primary cilia of Madin-Derby collecting duct cells in vitro (unpublished results). Definitive proof for an effect of Vangl2 mutations on ciliary functions or OCD has not been established and it remains unclear whether loss of Vangl2 contributes to polycystic kidney disease. This issue awaits the generation of conditional mutants with a renal excision of Vangl2 that survives into the postnatal period.

Luyten et al. showed that tubular inactivation of PKD1 in mature mice leads to cystogenesis, accompanied by loss of OCD and upregulation of the core PCP gene, Frizzled 3; elevated expression of Fz3 was noted in human ADPKD 
tissue [158]. Fz3 protein is expressed at the primary cilium in cells lining renal cysts but not in sister cells along normal segments of the tubule. The authors concluded that Fz3 becomes activated in the absence of $P K D 1$, leading to upregulation of Cdc42, rearrangements of actin, and loss of OCD [158]. Inappropriately elevated levels of $\mathrm{Fz} 3$ and randomized OCD were also detected in renal cysts induced by obstruction of the postnatal urinary tract [159].

Thorough examination of OCD in various mouse and rat models of polycystic kidney disease revealed a rather complex relationship between OCD, PCP, and cystogenesis. Bonnet et al. reported abnormal OCD in the tubules of young heterozygous PKD1-/+ mice; however, these mice develop only occasional cysts [160]. Humans with homozygous mutations of the PKHD1 gene (ARPKD) have widespread tubular dilatation and macrocysts; mice with homozygous PKHD1 mutations exhibit misaligned cell division in renal tubular cells, but curiously lack macrocysts in the kidney [161]. These observations suggest that PCP-dependent OCD may be disturbed in ARPKD but additional mechanisms may contribute to cystogenesis. In an elegant study by Karner et al., Wnt9b mutant mice were noted to have profound renal tubular dilation in the embryonic kidney [74]. Surprisingly, however, the authors discovered that cell division is oriented randomly in the embryonic period and mitotic spindles of dividing cells become polarized only postnatally during tubular elongation. Although cell number was normal in the dilated tubules of Wnt9b mutants, the ability of cells to undergo convergent extension was lost. Liu et al. reported that neonatal mice with the null mutation for another core PCP gene, Pricklel, exhibit tubular irregularities in various nephron compartments: proximal tubules were narrowed in the outer renal cortex and widened in the inner renal cortex; the cells of both collecting ducts and thick ascending loop of Henle were misshapen and misaligned [162]. At the cellular level, loss of Pricklel led to the defective polarity of the renal tubular cells. Importantly, approximately $5 \%$ of the mutant Prickle1-/- kidneys appeared cystic at birth [162].

The mechanics of tubular cell intercalation was further examined by observation of multicellular rosettes during Xenopus renal tubulogenesis [163]. The tubular rosette structure is highly similar to the rosettes seen during the Drosophila germ band extension and involves shrinkage of a mediolateral cell-cell boundary to form a rosette, with subsequent resolution of the cell-cell boundary in the perpendicular direction to produce CE [164]. However, whereas the Drosophila germ band elongation is independent of PCP signaling and is primarily regulated by myosin II [164], overexpression of dexamethasone-inducible Xdd1 expression construct (which was previously shown to affect PCP functions) leads to shorter, wider tubular structures [163].

Based on the observations above, it is quite plausible that disturbance of OCD and/or CE contributes to cystogenesis. However, the PCP-dependent mechanisms influencing cyst formation may differ according to developmental phase. During the mid-embryonic phase in mice, mutations of cilial genes may cause defective CE, whereas during early postnatal tubular elongation (or after postnatal injury such as ureteral obstruction) [159] mutant cilial genes may disturb OCD.
However, experimental proof for these temporally distinct PCP disturbances is lacking. While PCP clearly plays a role in tubulogenesis by facilitating both OCD and CE, the manner in which it is involved in human cystic kidney disease remains uncertain.

\section{Concluding Remarks}

Planar cell polarity genes were first identified in Drosophila, where pattern formation of extracellular appendages is easy to visualize. These genes encode a network of signaling molecules that reorganize the cytoskeleton to enable uniform localization of cellular structures. It is now well-established that mammals express homologues of fruit fly PCP genes and that PCP gene mutations disrupt key mammalian developmental processes such as neural tube closure and hair cell arrangement in the cochlea. On careful reflection, it is apparent that complex organs, such as the kidney, are organized along epithelial planes: cells of renal tubule are arranged so that dividing cells organize mitotic spindle alignment in the tubular plane to support linear tubular elongation; apical primary cilia are positioned and tilted uniformly to enable directional flow along the tubule to provide positional information; interdigitating podocyte foot processes are elegantly arranged along vascular flow through the capillaries which they envelop.

PCP gene homologs are expressed in the kidney and recent evidence has begun to uncover their functionality. Defects in branching morphogenesis were identified in $L P$ mice; this suggests that UB arborization relies on changes in cell shape [165], cell-cell adhesion, and movement [69]. In the future, it will be important to understand the role of Vangl2 and other PCP proteins in the behavior of UB tip cells and adjacent renal progenitor cells. In response to inductive WNT signals, progenitor cells must establish epithelial polarity, align themselves around a central lumen, and organize responses to the onset of directional tubular flow. At the same time, cells at the ureteric bud tip must undergo changes that support another round of branching morphogenesis. Thus, it is predictable that disturbance of PCP genes during this crucial phase would alter nephrogenesis. It will be important to understand how abrogation of PCP signaling in various cell lineages affects kidney development. The availability of CreLoxP-mediated PCP lines would certainly facilitate this task. Since unrestricted mutation of PCP genes may be embryonically lethal, the role of the PCP pathway in adult organs has been largely unexplored. Thus, conditional PCP gene knockout may provide missing information about the function of the PCP pathway in maintenance of adult kidney function as well.

Mutations of some PCP genes are associated with human neural tube defects [93]. Among NTD patients who survive into childhood, there is a high risk of developing progressive renal dysfunction. In the past, this has been attributed to secondary complications of neurogenic bladder rather than the possible renal manifestation of a primary PCP gene mutation. Interestingly, however, renal hypoplasia, duplicated collecting systems, and horseshoe kidneys have been reported 
in NTD patients $[166,167]$. Since PCP gene mutations cause renal malformations in mice, it may be timely to reconsider the etiology of renal problems in NTD patients [109].

While PCP is undoubtedly important for fly wings and mouse neural tubes, its potential importance in the kidney has largely been overlooked to date. From its role during ureteric bud branching and primary nephrogenesis to its involvement in the pathogenesis of congenital renal malformations and to the recovery from acquired renal disease in the adult, there is a great deal to learn about PCP in the kidney.

\section{Conflict of Interests}

The authors declare that they have no conflict of interests.

\section{Acknowledgments}

Brittany Rocque is an M.S. student supported by the McGill University Health Center Graduate Scholarship and McGill University Department of Physiology Graduate award; Elena Torban is supported by the Canadian Institute of Health Research Grants MOP102646 and MOP130315.

\section{References}

[1] F. Costantini and R. Kopan, "Patterning a complex organ: branching morphogenesis and nephron segmentation in kidney development," Developmental Cell, vol. 18, no. 5, pp. 698-712, 2010.

[2] G. R. Dressler, "The cellular basis of kidney development," Annual Review of Cell and Developmental Biology, vol. 22, pp. 509-529, 2006.

[3] I. V. Yosypiv, "Congenital anomalies of the kidney and urinary tract: a genetic disorder?" International Journal of Nephrology, vol. 2012, Article ID 909083, 10 pages, 2012.

[4] B. Margolis and J.-P. Borg, "Apicobasal polarity complexes," Journal of Cell Science, vol. 118, no. 22, pp. 5157-5159, 2005.

[5] W. J. Nelson, "Adaptation of core mechanisms to generate cell polarity," Nature, vol. 422, no. 6933, pp. 766-774, 2003.

[6] U. Tepass and E. Knust, "crumbs and stardust act in a genetic pathway that controls the organization of epithelia in Drosophila melanogaster," Developmental Biology, vol. 159, no. 1, pp. 311-326, 1993.

[7] D. Bilder, M. Schober, and N. Perrimon, "Integrated activity of PDZ protein complexes regulates epithelial polarity," Nature Cell Biology, vol. 5, no. 1, pp. 53-58, 2003.

[8] F. Martin-Belmonte and K. Mostov, "Regulation of cell polarity during epithelial morphogenesis," Current Opinion in Cell Biology, vol. 20, no. 2, pp. 227-234, 2008.

[9] J. Pieczynski and B. Margolis, "Protein complexes that control renal epithelial polarity," The American Journal of PhysiologyRenal Physiology, vol. 300, no. 3, pp. F589-F601, 2011.

[10] L. V. Goodrich and D. Strutt, "Principles of planar polarity in animal development," Development, vol. 138, no. 10, pp. 18771892, 2011.

[11] H. Strutt and D. Strutt, "Asymmetric localisation of planar polarity proteins: mechanisms and consequences," Seminars in Cell and Developmental Biology, vol. 20, no. 8, pp. 957-963, 2009.
[12] D. Gubb and A. Garcia-Bellido, "A genetic analysis of the determination of cuticular polarity during development in Drosophila melanogaster," Journal of Embryology and Experimental Morphology, vol. 68, pp. 37-57, 1982.

[13] L. L. Wong and P. N. Adler, "Tissue polarity genes of Drosophila regulate the subcellular location for prehair initiation in pupal wing cells," Journal of Cell Biology, vol. 123, no. 1, pp. 209-221, 1993.

[14] C. R. Vinson and P. N. Adler, "Directional non-cell autonomy and the transmission of polarity information by the frizzled gene of Drosophila," Nature, vol. 329, no. 6139, pp. 549-551, 1987.

[15] H. McNeill, "Planar cell polarity and the kidney," Journal of the American Society of Nephrology, vol. 20, no. 10, pp. 2104-2111, 2009.

[16] E. Papakrivopoulou, C. H. Dean, A. J. Copp, and D. A. Long, "Planar cell polarity and the kidney," Nephrology Dialysis Transplantation, vol. 29, no. 7, pp. 1320-1326, 2014.

[17] F. Costantini, "Renal branching morphogenesis: concepts, questions, and recent advances," Differentiation, vol. 74, no. 7, pp. 402-421, 2006.

[18] A. Kobayashi, M. T. Valerius, J. W. Mugford et al., "Six2 defines and regulates a multipotent self-renewing nephron progenitor population throughout mammalian kidney development," Cell Stem Cell, vol. 3, no. 2, pp. 169-181, 2008.

[19] J. Xu, H. Liu, J.-S. Park, Y. Lan, and R. Jiang, "Osrl acts downstream of and interacts synergistically with Six 2 to maintain nephron progenitor cells during kidney organogenesis," Development, vol. 141, no. 7, pp. 1442-1452, 2014.

[20] T. J. Carroll, J.-S. Park, S. Hayashi, A. Majumdar, and A. P. McMahon, "Wnt9b plays a central role in the regulation of mesenchymal to epithelial transitions underlying organogenesis of the mammalian urogenital system," Developmental Cell, vol. 9, no. 2, pp. 283-292, 2005.

[21] S. Sarin, F. Boivin, A. Li et al., " $\beta$-Catenin overexpression in the metanephric mesenchyme leads to renal dysplasia genesis via cell-autonomous and non-cell-autonomous mechanisms," American Journal of Pathology, vol. 184, no. 5, pp. 1395-1410, 2014.

[22] D. Bridgewater, B. Cox, J. Cain et al., "Canonical WNT/ $\beta$ catenin signaling is required for ureteric branching," Developmental Biology, vol. 317, no. 1, pp. 83-94, 2008.

[23] M. Torres, E. Gómez-Pardo, G. R. Dressler, and P. Gruss, "Pax-2 controls multiple steps of urogenital development," Development, vol. 121, no. 12, pp. 4057-4065, 1995.

[24] J. G. Pichel, L. Shen, H. Z. Sheng et al., "Defects in enteric innervation and kidney development in mice lacking GDNF," Nature, vol. 382, no. 6586, pp. 73-76, 1996.

[25] A. Schuchardt, V. D’Agati, L. Larsson-Blornberg, F. Costantini, and V. Pachnis, "Defects in the kidney and enteric nervous system of mice lacking the tyrosine kinase receptor Ret," Nature, vol. 367, no. 6461, pp. 380-383, 1994.

[26] A. C. Tomac, A. Grinberg, S. P. Huang et al., "Glial cell linederived neurotrophic factor receptor $\alpha 1$ availability regulates glial cell line-derived neurotrophic factor signaling: evidence from mice carrying one or two mutated alleles," Neuroscience, vol. 95, no. 4, pp. 1011-1023, 1999.

[27] P.-X. Xu, J. Adams, H. Peters, M. C. Brown, S. Heaney, and R. Maas, "Eyal-deficient mice lack ears and kidneys and show abnormal apoptosis of organ primordia," Nature Genetics, vol. 23, no. 1, pp. 113-117, 1999. 
[28] L. T. Patterson, M. Pembaur, and S. S. Potter, "Hoxall and Hoxd11 regulate branching morphogenesis of the ureteric bud in the developing kidney," Development, vol. 128, no. 11, pp. 2153-2161, 2001.

[29] D. Grote, S. K. Boualia, A. Souabni et al., "Gata3 acts downstream of beta-catenin signaling to prevent ectopic metanephric kidney induction," PLoS Genetics, vol. 4, no. 12, Article ID e1000316, 2008.

[30] J. W. Mugford, J. Yu, A. Kobayashi, and A. P. McMahon, "Highresolution gene expression analysis of the developing mouse kidney defines novel cellular compartments within the nephron progenitor population," Developmental Biology, vol. 333, no. 2, pp. 312-323, 2009.

[31] R. Kopan, H.-T. Cheng, and K. Surendran, "Molecular insights into segmentation along the proximal-distal axis of the nephron," Journal of the American Society of Nephrology, vol. 18, no. 7, pp. 2014-2020, 2007.

[32] K. A. McLaughlin, M. S. Rones, and M. Mercola, "Notch regulates cell fate in the developing pronephros," Developmental Biology, vol. 227, no. 2, pp. 567-580, 2000.

[33] H.-T. Cheng, J. H. Miner, M. Lin, M. G. Tansey, K. Roth, and R. Kopan, " $\gamma$-secretase activity is dispensable for mesenchyme-toepithelium transition but required for podocyte and proximal tubule formation in developing mouse kidney," Development, vol. 130, no. 20, pp. 5031-5042, 2003.

[34] P. Wang, F. A. Pereira, D. Beasley, and H. Zheng, "Presenilins are required for the formation of comma- and S-shaped bodies during nephrogenesis," Development, vol. 130, no. 20, pp. 50195029, 2003.

[35] H.-T. Cheng, M. Kim, M. T. Valerius et al., "Notch2, but not Notch1, is required for proximal fate acquisition in the mammalian nephron," Development, vol. 134, no. 4, pp. 801-811, 2007.

[36] K. Georgas, B. Rumballe, L. Wilkinson et al., "Use of dual section mRNA in situ hybridisation/immunohistochemistry to clarify gene expression patterns during the early stages of nephron development in the embryo and in the mature nephron of the adult mouse kidney," Histochemistry and Cell Biology, vol. 130, no. 5, pp. 927-942, 2008.

[37] M. J. McConnell, H. E. Cunliffe, L. J. Chua, T. A. Ward, and M. R. Eccles, "Differential regulation of the human Wilms tumour suppressor gene (WT1) promoter by two isoforms of PAX2," Oncogene, vol. 14, no. 22, pp. 2689-2700, 1997.

[38] J. A. Davies, M. Ladomery, P. Hohenstein et al., "Development of an siRNA-based method for repressing specific genes in renal organ culture and its use to show that the Wt1 tumour suppressor is required for nephron differentiation," Human Molecular Genetics, vol. 13, no. 2, pp. 235-246, 2004.

[39] M. T. Discenza, S. He, T. H. Lee et al., "WT1 is a modifier of the Pax2 mutant phenotype: cooperation and interaction between WT1 and Pax2," Oncogene, vol. 22, no. 50, pp. 8145-8155, 2003.

[40] G. Ryan, V. Steele-Perkins, J. F. Morris, F. J. Rauscher III, and G. R. Dressler, "Repression of Pax-2 by WT1 during normal kidney development," Development, vol. 121, no. 3, pp. 867-875, 1995.

[41] S. E. Quaggin and J. A. Kreidberg, "Development of the renal glomerulus: good neighbors and good fences," Development, vol. 135, no. 4, pp. 609-620, 2008.

[42] P. A. Lawrence and P. M. J. Shelton, "The determination of polarity in the developing insect retina," Journal of Embryology and Experimental Morphology, vol. 33, no. 2, pp. 471-486, 1975.

[43] M. A. Simon, "Planar cell polarity in the Drosophila eye is directed by graded four-jointed and Dachsous expression," Development, vol. 131, no. 24, pp. 6175-6184, 2004.
[44] H. Strutt, J. Mundy, K. Hofstra, and D. Strutt, "Cleavage and secretion is not required for four-jointed function in Drosophila patterning," Development, vol. 131, no. 4, pp. 881-890, 2004.

[45] H. O. Ishikawa, H. Takeuchi, R. S. Haltiwanger, and K. D. Irvine, "Four-jointed is a Golgi kinase that phosphorylates a subset of cadherin domains," Science, vol. 321, no. 5887, pp. 401-404, 2008.

[46] H. Strutt and D. Strutt, "Long-range coordination of planar polarity in Drosophila," BioEssays, vol. 27, no. 12, pp. 1218-1227, 2005.

[47] D. Strutt, "Frizzled signalling and cell polarisation in Drosophila and vertebrates," Development, vol. 130, no. 19, pp. 4501-4513, 2003.

[48] J. Wu, A.-C. Roman, J. M. Carvajal-Gonzalez, and M. Mlodzik, "Wg and Wnt4 provide long-range directional input to planar cell polarity orientation in Drosophila," Nature Cell Biology, vol. 15, no. 9, pp. 1045-1055, 2013.

[49] Y. Wang, J. Yan, H. Lee, Q. Lu, and P. N. Adler, “The proteins encoded by the Drosophila Planar Polarity Effector genes inturned, fuzzy and fritz interact physically and can re-pattern the accumulation of 'upstream' Planar Cell Polarity proteins," Developmental Biology, vol. 394, no. 1, pp. 156-169, 2014.

[50] J.-R. Courbard, A. Djiane, J. Wu, and M. Mlodzik, "The apical/basal-polarity determinant Scribble cooperates with the PCP core factor Stbm/Vang and functions as one of its effectors," Developmental Biology, vol. 333, no. 1, pp. 67-77, 2009.

[51] J. Yan, Q. Lu, X. Fang, and P. N. Adler, "Rhol has multiple functions in Drosophila wing planar polarity," Developmental Biology, vol. 333, no. 1, pp. 186-199, 2009.

[52] M. Fanto, U. Weber, D. I. Strutt, and M. Mlodzik, "Nuclear signaling by Rac and Rho GTPases is required in the establishment of epithelial planar polarity in the Drosophila eye," Current Biology, vol. 10, no. 16, pp. 979-988, 2000.

[53] D. I. Strutt, U. Weber, and M. Mlodzik, "The role of RhoA in tissue polarity and frizzled signalling," Nature, vol. 387, no. 6630, pp. 292-295, 1997.

[54] C. G. Winter, B. Wang, A. Ballew et al., "Drosophila Rhoassociated kinase (Drok) links Frizzled-mediated planar cell polarity signaling to the actin cytoskeleton," Cell, vol. 105, no. 1, pp. 81-91, 2001.

[55] J. A. Kaltschmidt, N. Lawrence, V. Morel et al., "Planar polarity and actin dynamics in the epidermis of Drosophila," Nature Cell Biology, vol. 4, no. 12, pp. 937-944, 2002.

[56] U. Weber, N. Paricio, and M. Mlodzik, "Jun mediates Frizzledinduced R3/R4 cell fate distinction and planar polarity determination in the Drosophila eye," Development, vol. 127, no. 16, pp. 3619-3629, 2000.

[57] M. Matis, D. A. Russler-Germain, Q. Hu, C. J. Tomlin, and J. D. Axelrod, "Microtubules provide directional information for core PCP function," eLife, Article ID e02893, 2014.

[58] J. Casal, P. A. Lawrence, and G. Struhl, "Two separate molecular systems, Dachsous/Fat and Starry night/Frizzled, act independently to confer planar star polarity," Development, vol. 133, no. 22, pp. 4561-4572, 2006.

[59] J. M. Carvajal-Gonzalez and M. Mlodzik, "Mechanisms of planar cell polarity establishment in Drosophila," F1000Prime Reports, vol. 6, article 98, 2014.

[60] J. D. Axelrod, "Unipolar membrane association of Dishevelled mediates Frizzled planar cell polarity signaling," Genes and Development, vol. 15, no. 10, pp. 1182-1187, 2001.

[61] R. Bastock, H. Strutt, and D. Strutt, "Strabismus is asymmetrically localised and binds to Prickle and Dishevelled during 
Drosophila planar polarity patterning," Development, vol. 130, no. 13, pp. 3007-3014, 2003.

[62] D. I. Strutt, "Asymmetric localization of frizzled and the establishment of cell polarity in the Drosophila wing," Molecular Cell, vol. 7, no. 2, pp. 367-375, 2001.

[63] D. R. P. Tree, J. M. Shulman, R. Rousset, M. P. Scott, D. Gubb, and J. D. Axelrod, "Prickle mediates feedback amplification to generate asymmetric planar cell polarity signaling," Cell, vol. 109, no. 3, pp. 371-381, 2002.

[64] A. S. Rawls and T. Wolff, "Strabismus requires flamingo and prickle function to regulate tissue polarity in the Drosophila eye," Development, vol. 130, no. 9, pp. 1877-1887, 2003.

[65] G. Das, A. Jenny, T. J. Klein, S. Eaton, and M. Mlodzik, "Diego interacts with Prickle and Strabismus/Van Gogh to localize planar cell polarity complexes," Development, vol. 131, no. 18, pp. 4467-4476, 2004.

[66] J. Wu and M. Mlodzik, "The frizzled extracellular domain is a ligand for Van Gogh/Stbm during nonautonomous planar cell polarity signaling," Developmental Cell, vol. 15, no. 3, pp. 462469, 2008.

[67] M. Narimatsu, R. Bose, M. Pye et al., "Regulation of planar cell polarity by Smurf ubiquitin ligases," Cell, vol. 137, no. 2, pp. 295307, 2009.

[68] J. Yan, D. Huen, T. Morely et al., "The multiple-wing-hairs gene encodes a novel GBD-FH3 domain-containing protein that functions both prior to and after wing hair initiation," Genetics, vol. 180, no. 1, pp. 219-228, 2008.

[69] A.-K. Classen, K. I. Anderson, E. Marois, and S. Eaton, "Hexagonal packing of Drosophila wing epithelial cells by the planar cell polarity pathway," Developmental Cell, vol. 9, no. 6, pp. 805-817, 2005.

[70] S. J. Warrington, H. Strutt, and D. Strutt, "The frizzleddependent planar polarity pathway locally promotes Ecadherin turnover via recruitment of RhoGEF2," Development, vol. 140, no. 5, pp. 1045-1054, 2013.

[71] C.-P. Heisenberg, M. Tada, G.-J. Rauch et al., "Silberblick/Wnt11 mediates convergent extension movements during zebrafish gastrulation," Nature, vol. 405, no. 6782, pp. 76-81, 2000.

[72] D. G. McEwen and M. Peifer, "Wnt signaling: moving in a new direction," Current Biology, vol. 10, no. 15, pp. R562-R564, 2000.

[73] M. Tada and J. C. Smith, "Xwnt11 is a target of Xenopus Brachyury: regulation of gastrulation movements via Dishevelled, but not through the canonical Wnt pathway," Development, vol. 127, no. 10, pp. 2227-2238, 2000.

[74] C. M. Karner, R. Chirumamilla, S. Aoki, P. Igarashi, J. B. Wallingford, and T. J. Carroll, "Wnt9b signaling regulates planar cell polarity and kidney tubule morphogenesis," Nature Genetics, vol. 41, no. 7, pp. 793-799, 2009.

[75] Z. Kibar, K. J. Vogan, N. Groulx, M. J. Justice, D. A. Underhill, and P. Gros, "Ltap, a mammalian homolog of Drosophila strabismus/Van Gogh, is altered in the mouse neural tube mutant Loop-tail," Nature Genetics, vol. 28, pp. 251-255, 2001.

[76] T. J. Park, S. L. Haigo, and J. B. Wallingford, "Ciliogenesis defects in embryos lacking inturned or fuzzy function are associated with failure of planar cell polarity and Hedgehog signaling," Nature Genetics, vol. 38, no. 3, pp. 303-311, 2006.

[77] R. S. Gray, P. B. Abitua, B. J. Wlodarczyk et al., “The planar cell polarity effector Fuz is essential for targeted membrane trafficking, ciliogenesis and mouse embryonic development," Nature Cell Biology, vol. 11, no. 10, pp. 1225-1232, 2009.
[78] H. Zeng, A. N. Hoover, and A. Liu, "PCP effector gene Inturned is an important regulator of cilia formation and embryonic development in mammals," Developmental Biology, vol. 339, no. 2, pp. 418-428, 2010.

[79] J. N. Murdoch, D. J. Henderson, K. Doudney et al., "Disruption of scribble (Scrb1) causes severe neural tube defects in the circletail mouse," Human Molecular Genetics, vol. 12, no. 2, pp. 87-98, 2003.

[80] X. Lu, A. G. M. Borchers, C. Jolicoeur, H. Rayburn, J. C. Baker, and M. Tessier-Lavigne, "PTK7/CCK-4 is a novel regulator of planar cell polarity in vertebrates," Nature, vol. 430, no. 6995, pp. 93-98, 2004.

[81] M. Montcouquiol, R. A. Rachel, P. J. Lanford, N. G. Copeland, N. A. Jenkins, and M. W. Kelley, "Identification of Vangl2 and Scrb1 as planar polarity genes in mammals," Nature, vol. 423, no. 6936, pp. 173-177, 2003.

[82] N. Guo, C. Hawkins, and J. Nathans, "Frizzled6 controls hair patterning in mice," Proceedings of the National Academy of Sciences of the United States of America, vol. 101, no. 25, pp. 92779281, 2004.

[83] E. Torban, A.-M. Patenaude, S. Leclerc et al., "Genetic interaction between members of the Vangl family causes neural tube defects in mice," Proceedings of the National Academy of Sciences of the United States of America, vol. 105, no. 9, pp. 3449-3454, 2008.

[84] J. N. Murdoch, K. Doudney, C. Paternotte, A. J. Copp, and P. Stanier, "Severe neural tube defects in the loop-tail mouse result from mutation of Lpp1, a novel gene involved in floor plate specification," Human Molecular Genetics, vol. 10, no. 22, pp. 2593-2601, 2001.

[85] S. L. Etheridge, S. Ray, S. Li et al., "Murine dishevelled 3 functions in redundant pathways with dishevelled 1 and 2 in normal cardiac outflow tract, cochlea, and neural tube development," PLoS Genetics, vol. 4, no. 11, Article ID e1000259, 2008.

[86] D. J. Henderson, H. M. Phillips, and B. Chaudhry, "Vang-like 2 and noncanonical Wnt signaling in outflow tract development," Trends in Cardiovascular Medicine, vol. 16, no. 2, pp. 38-45, 2006.

[87] H. M. Phillips, J. N. Murdoch, B. Chaudhry, A. J. Copp, and D. J. Henderson, "Vangl2 acts via RhoA signaling to regulate polarized cell movements during development of the proximal outflow tract," Circulation Research, vol. 96, no. 3, pp. 292-299, 2005.

[88] H. Yu, X. Ye, N. Guo, and J. Nathans, "Frizzled 2 and frizzled 7 function redundantly in convergent extension and closure of the ventricular septum and palate: evidence for a network of interacting genes," Development, vol. 139, no. 23, pp. 4383-4394, 2012.

[89] N. S. Hamblet, N. Lijam, P. Ruiz-Lozano et al., "Dishevelled 2 is essential for cardiac outflow tract development, somite segmentation and neural tube closure," Development, vol. 129, no. 24, pp. 5827-5838, 2002.

[90] L. L. Yates, C. Schnatwinkel, J. N. Murdoch et al., "The PCP genes Celsrl and Vangl2 are required for normal lung branching morphogenesis," Human Molecular Genetics, vol. 19, no. 11, pp. 2251-2267, 2010

[91] J. A. Curtin, E. Quint, V. Tsipouri et al., "Mutation of Celsr1 disrupts planar polarity of inner ear hair cells and causes severe neural tube defects in the mouse," Current Biology, vol. 13, no. 13, pp. 1129-1133, 2003.

[92] Y. Wang, N. Guo, and J. Nathans, "The role of Frizzled3 and Frizzled6 in neural tube closure and in the planar polarity of 
inner-ear sensory hair cells," The Journal of Neuroscience, vol. 26, no. 8, pp. 2147-2156, 2006.

[93] N. D. Greene and A. J. Copp, "Neural tube defects," Annual Review of Neuroscience, vol. 37, no. 1, pp. 221-242, 2014.

[94] J. B. Wallingford, L. A. Niswander, G. M. Shaw, and R. H. Finnell, "The continuing challenge of understanding, preventing, and treating neural tube defects," Science, vol. 339, no. 6123, 2013.

[95] J. B. Wallingford and R. M. Harland, "Xenopus Dishevelled signaling regulates both neural and mesodermal convergent extension: parallel forces elongating the body axis," Development, vol. 128, no. 13, pp. 2581-2592, 2001.

[96] J. B. Wallingford and R. M. Harland, "Neural tube closure requires Dishevelled-dependent convergent extension of the midline," Development, vol. 129, no. 24, pp. 5815-5825, 2002.

[97] R. E. Keller, M. Danilchik, R. Gimlich, and J. Shih, “The function and mechanism of convergent extension during gastrulation of Xenopus laevis," Journal of Embryology and Experimental Morphology, vol. 89, supplement, pp. 185-209, 1985.

[98] S. Y. Sokol, "Analysis of Dishevelled signalling pathways during Xenopus development," Current Biology, vol. 6, no. 11, pp. 14561467, 1996.

[99] J. B. Wallingford, B. A. Rowning, K. M. Vogell, U. Rothbächer, S. E. Fraser, and R. M. Harland, "Dishevelled controls cell polarity during Xenopus gastrulation," Nature, vol. 405, no. 6782, pp. 8185, 2000.

[100] P. Ybot-Gonzalez, D. Savery, D. Gerrelli et al., "Convergent extension, planar-cell-polarity signaling and initiation of mouse neural tube closure," Development, vol. 134, no. 4, pp. 789-799, 2007.

[101] J. H. Seo, Y. Zilber, S. Babayeva et al., "Mutations in the planar cell polarity gene, fuzzy, are associated with neural tube defects in humans," Human Molecular Genetics, vol. 20, no. 22, pp. 4324-4333, 2011.

[102] W. Heydeck, H. Zeng, and A. Liu, "Planar cell polarity effector gene Fuzzy regulates cilia formation and hedgehog signal transduction in mouse," Developmental Dynamics, vol. 238, no. 12, pp. 3035-3042, 2009.

[103] T. J. Park, B. J. Mitchell, P. B. Abitua, C. Kintner, and J. B. Wallingford, "Dishevelled controls apical docking and planar polarization of basal bodies in ciliated epithelial cells," Nature Genetics, vol. 40, no. 7, pp. 871-879, 2008.

[104] S. Ohata, J. Nakatani, V. Herranz-Perez et al., "Loss of Dishevelleds disrupts planar polarity in ependymal motile cilia and results in hydrocephalus," Neuron, vol. 83, no. 3, pp. 558-571, 2014.

[105] M. Hashimoto, K. Shinohara, J. Wang et al., "Planar polarization of node cells determines the rotational axis of node cilia," Nature Cell Biology, vol. 12, no. 2, pp. 170-176, 2010.

[106] F. Tissir, Y. Qu, M. Montcouquiol et al., "Lack of cadherins Celsr2 and Celsr3 impairs ependymal ciliogenesis, leading to fatal hydrocephalus," Nature Neuroscience, vol. 13, no. 6, pp. 700-707, 2010.

[107] E. K. Vladar, R. D. Bayly, A. M. Sangoram, M. P. Scott, and J. D. Axelrod, "Microtubules enable the planar cell polarity of airway cilia," Current Biology, vol. 22, no. 23, pp. 2203-2212, 2012.

[108] S. Babayeva, B. Rocque, L. Aoudjit et al., "Planar cell polarity pathway regulates nephrin endocytosis in developing podocytes," The Journal of Biological Chemistry, vol. 288, no. 33, pp. 24035-24048, 2013.
[109] L. L. Yates, J. Papakrivopoulou, D. A. Long et al., “The planar cell polarity gene Vangl2 is required for mammalian kidneybranching morphogenesis and glomerular maturation," Human Molecular Genetics, vol. 19, no. 23, pp. 4663-4676, 2010.

[110] S. Saburi, I. Hester, E. Fischer et al., "Loss of Fat4 disrupts PCP signaling and oriented cell division and leads to cystic kidney disease," Nature Genetics, vol. 40, no. 8, pp. 1010-1015, 2008.

[111] K. Yun, R. Ajima, N. Sharma et al., "Non-canonical Wnt5a/Ror2 signaling regulates kidney morphogenesis by controlling intermediate mesoderm extension," Human Molecular Genetics, vol. 23, no. 25, pp. 6807-6814, 2014.

[112] C. M. Karner, A. Das, Z. Ma et al., "Canonical Wnt9b signaling balances progenitor cell expansion and differentiation during kidney development," Development, vol. 138, no. 7, pp. 12471257, 2011.

[113] A. Majumdar, S. Vainio, A. Kispert, J. McMahon, and A. P. McMahon, "Wntll and Ret/Gdnf pathways cooperate in regulating ureteric branching during metanephric kidney development," Development, vol. 130, no. 14, pp. 3175-3185, 2003.

[114] R. van Amerongen, C. Fuerer, M. Mizutani, and R. Nusse, "Wnt5a can both activate and repress Wnt/B-catenin signaling during mouse embryonic development," Developmental Biology, vol. 369, no. 1, pp. 101-114, 2012.

[115] P. Goggolidou, "Wnt and planar cell polarity signaling in cystic renal disease," Organogenesis, vol. 10, no. 1, pp. 86-95, 2014.

[116] M. Simons, J. Gloy, A. Ganner et al., "Inversin, the gene product mutated in nephronophthisis type II, functions as a molecular switch between Wnt signaling pathways," Nature Genetics, vol. 37, no. 5, pp. 537-543, 2005.

[117] R. Allache, S. Lachance, M. C. Guyot et al., "Novel mutations in Lrp6 orthologs in mouse and human neural tube defects affect a highly dosage-sensitive Wnt non-canonical planar cell polarity pathway," Human Molecular Genetics, vol. 23, no. 7, pp. 16871699, 2014.

[118] Y. Zilber, S. Babayeva, J. H. Seo, J. J. Liu, S. Mootin, and E. Torban, "The PCP effector Fuzzy controls cilial assembly and signaling by recruiting Rab8 and Dishevelled to the primary cilium," Molecular Biology of the Cell, vol. 24, no. 5, pp. 555-565, 2013.

[119] S. Babayeva, Y. Zilber, and E. Torban, "Planar cell polarity pathway regulates actin rearrangement, cell shape, motility, and nephrin distribution in podocytes," The American Journal of Physiology-Renal Physiology, vol. 300, no. 2, pp. F549-F560, 2011.

[120] X. Ye, Y. Wang, A. Rattner, and J. Nathans, "Genetic mosaic analysis reveals a major role for frizzled 4 and frizzled 8 in controlling ureteric growth in the developing kidney," Development, vol. 138, no. 6, pp. 1161-1172, 2011.

[121] S. Porteous, E. Torban, C. Nam-Pyo et al., "Primary renal hypoplasia in humans and mice with PAX2 mutations: evidence of increased apoptosis in fetal kidneys of Pax2(1Neu) +/mutant mice," Human Molecular Genetics, vol. 9, no. 1, pp. 1-11, 2000.

[122] A. Andreeva, J. Lee, M. Lohia, X. Wu, I. G. Macara, and X. Lu, "PTK7-Src signaling at epithelial cell contacts mediates spatial organization of actomyosin and planar cell polarity," Developmental Cell, vol. 29, no. 1, pp. 20-33, 2014.

[123] S. Saburi, I. Hester, L. Goodrich, and H. McNeill, "Functional interactions between Fat family cadherins in tissue morphogenesis and planar polarity," Development, vol. 139, no. 10, pp. 18061820, 2012. 
[124] B. L. Rocque, S. Babayeva, J. Li et al., "Deficiency of the planar cell polarity protein vangl2 in podocytes affects glomerular morphogenesis and increases susceptibility to injury," Journal of the American Society of Nephrology, 2014.

[125] J. Wells, M. N. Rivera, W. J. Kim, K. Starbuck, and D. A. Haber, "The predominant WT1 isoform (+KTS) encodes a DNA-binding protein targeting the planar cell polarity gene Scribble in renal podocytes," Molecular Cancer Research, vol. 8, no. 7, pp. 975-985, 2010.

[126] B. Hartleben, E. Widmeier, N. Wanner et al., "Role of the polarity protein Scribble for podocyte differentiation and maintenance," PLoS ONE, vol. 7, no. 5, Article ID e36705, 2012.

[127] M. Žigman, L. A. Trinh, S. E. Fraser, and C. B. Moens, "Zebrafish neural tube morphogenesis requires scribble-dependent oriented cell divisions," Current Biology, vol. 21, no. 1, pp. 79-86, 2011.

[128] L. Ciani, A. Patel, N. D. Allen, and C. Ffrench-Constant, "Mice lacking the giant protocadherin mFAT1 exhibit renal slit junction abnormalities and a partially penetrant cyclopia and anophthalmia phenotype," Molecular and Cellular Biology, vol. 23, no. 10, pp. 3575-3582, 2003.

[129] M. J. Harris and D. M. Juriloff, "An update to the list of mouse mutants with neural tube closure defects and advances toward a complete genetic perspective of neural tube closure," Birth Defects Research Part A-Clinical and Molecular Teratology, vol. 88, no. 8, pp. 653-669, 2010.

[130] E. Yaoita, H. Kurihara, Y. Yoshida et al., "Role of Fat1 in cell-cell contact formation of podocytes in puromycin aminonucleoside nephrosis and neonatal kidney," Kidney International, vol. 68, no. 2, pp. 542-551, 2005.

[131] H. Happé, E. de Heer, and D. J. M. Peters, "Polycystic kidney disease: the complexity of planar cell polarity and signaling during tissue regeneration and cyst formation," Biochimica et Biophysica Acta - Molecular Basis of Disease, vol. 1812, no. 10, pp. 1249-1255, 2011.

[132] L. F. Menezes and G. G. Germino, "Polycystic kidney disease, cilia, and planar polarity," Methods in Cell Biology, vol. 94, pp. 273-297, 2009.

[133] F. Hildebrandt, T. Benzing, and N. Katsanis, "Ciliopathies," The New England Journal of Medicine, vol. 364, no. 16, pp. 1533-1543, 2011.

[134] E. C. Oh and N. Katsanis, "Cilia in vertebrate development and disease," Development, vol. 139, no. 3, pp. 443-448, 2012.

[135] J. T. Eggenschwiler and K. V. Anderson, "Cilia and developmental signaling," Annual Review of Cell and Developmental Biology, vol. 23, pp. 345-373, 2007.

[136] J. M. Gerdes, E. E. Davis, and N. Katsanis, "The vertebrate primary cilium in development, homeostasis, and disease," Cell, vol. 137, no. 1, pp. 32-45, 2009.

[137] J. M. Gerdes and N. Katsanis, "Ciliary function and Wnt signal modulation," Current Topics in Developmental Biology, vol. 85, pp. 175-195, 2008.

[138] J. B. Wallingford and B. Mitchell, "Strange as it may seem: the many links between Wnt signaling, planar cell polarity, and cilia," Genes and Development, vol. 25, no. 3, pp. 201-213, 2011.

[139] K. C. Corbit, A. E. Shyer, W. E. Dowdle, J. Gaulden, V. Singla, and J. F. Reiter, "Kif3a constrains $\beta$-catenin-dependent Wnt signalling through dual ciliary and non-ciliary mechanisms," Nature Cell Biology, vol. 10, no. 1, pp. 70-76, 2008.

[140] C. Jones, V. C. Roper, I. Foucher et al., "Ciliary proteins link basal body polarization to planar cell polarity regulation," Nature Genetics, vol. 40, no. 1, pp. 69-77, 2008.
[141] E. A. Otto, B. Schermer, T. Obara et al., "Mutations in INVS encoding inversin cause nephronophthisis type 2 , linking renal cystic disease to the function of primary cilia and left-right axis determination," Nature Genetics, vol. 34, no. 4, pp. 413-420, 2003.

[142] F. Feiguin, M. Hannus, M. Mlodzik, and S. Eaton, “The ankyrin repeat protein Diego mediates Frizzled-dependent planar polarization," Developmental Cell, vol. 1, no. 1, pp. 93-101, 2001.

[143] Y. Bellache, A. Radovic, D. F. Woods et al., "The Partner of Inscuteable/Discs-large complex is required to establish planar polarity during asymmetric cell division in Drosophila," Cell, vol. 106, no. 3, pp. 355-366, 2001.

[144] Y. Gong, C. Mo, and S. E. Fraser, "Planar cell polarity signalling controls cell division orientation during zebrafish gastrulation," Nature, vol. 430, no. 7000, pp. 689-693, 2004.

[145] G. G. Germino, "Linking cilia to Wnts," Nature Genetics, vol. 37, no. 5, pp. 455-457, 2005.

[146] E. Fischer, E. Legue, A. Doyen et al., "Defective planar cell polarity in polycystic kidney disease," Nature Genetics, vol. 38, no. 1, pp. 21-23, 2006.

[147] C. Bingham and A. T. Hattersley, "Renal cysts and diabetes syndrome resulting from mutations in hepatocyte nuclear factor-1beta," Nephrology Dialysis Transplantation, vol. 19, no. 11, pp. 2703-2708, 2004.

[148] M. Kyttälä, J. Tallila, R. Salonen et al., " $M K S 1$, encoding a component of the flagellar apparatus basal body proteome, is mutated in Meckel syndrome," Nature Genetics, vol. 38, no. 2, pp. 155-157, 2006.

[149] S. D. Weatherbee, L. A. Niswander, and K. V. Anderson, "A mouse model for Meckel syndrome reveals Mks1 is required for ciliogenesis and Hedgehog signaling," Human Molecular Genetics, vol. 18, no. 23, pp. 4565-4575, 2009.

[150] F.-X. Yu and K.-L. Guan, "The Hippo pathway: regulators and regulations," Genes and Development, vol. 27, no. 4, pp. 355-371, 2013.

[151] R. Makita, Y. Uchijima, K. Nishiyama et al., "Multiple renal cysts, urinary concentration defects, and pulmonary emphysematous changes in mice lacking TAZ," The American Journal of Physiology-Renal Physiology, vol. 294, no. 3, pp. F542-F553, 2008.

[152] H. Happé, A. M. van der Wal, W. N. Leonhard et al., "Altered Hippo signalling in polycystic kidney disease," The Journal of Pathology, vol. 224, no. 1, pp. 133-142, 2011.

[153] A. Borovina, S. Superina, D. Voskas, and B. Ciruna, "Vangl2 directs the posterior tilting and asymmetric localization of motile primary cilia," Nature Cell Biology, vol. 12, no. 4, pp. 407$412,2010$.

[154] H. Song, J. Hu, W. Chen et al., "Planar cell polarity breaks bilateral symmetry by controlling ciliary positioning," Nature, vol. 466, no. 7304, pp. 378-382, 2010.

[155] D. Antic, J. L. Stubbs, K. Suyama, C. Kintner, M. P. Scott, and J. D. Axelrod, "Planar cell polarity enables posterior localization of nodal cilia and left-right axis determination during mouse and Xenopus embryogenesis," PLoS ONE, vol. 5, no. 2, Article ID e8999, 2010.

[156] H. L. May-Simera, M. Kai, V. Hernandez, D. P. S. Osborn, M. Tada, and P. L. Beales, "Bbs8, together with the planar cell polarity protein Vangl2, is required to establish left-right asymmetry in zebrafish," Developmental Biology, vol. 345, no. 2, pp. 215-225, 2010. 
[157] A. J. Ross, H. May-Simera, E. R. Eichers et al., "Disruption of Bardet-Biedl syndrome ciliary proteins perturbs planar cell polarity in vertebrates," Nature Genetics, vol. 37, no. 10, pp. 11351140, 2005.

[158] A. Luyten, X. Su, S. Gondela et al., "Aberrant regulation of planar cell polarity in polycystic kidney disease," Journal of the American Society of Nephrology, vol. 21, no. 9, pp. 1521-1532, 2010.

[159] L. Li, D. Zepeda-Orozco, V. Patel et al., "Aberrant planar cell polarity induced by urinary tract obstruction," The American Journal of Physiology-Renal Physiology, vol. 297, no. 6, pp. F1526-F1533, 2009.

[160] C. S. Bonnet, M. Aldred, C. Von Ruhland, R. Harris, R. Sandford, and J. P. Cheadle, "Defects in cell polarity underlie TSC and ADPKD-associated cystogenesis," Human Molecular Genetics, vol. 18, no. 12, pp. 2166-2176, 2009.

[161] S. Nishio, X. Tian, A. R. Gallagher et al., "Loss of oriented cell division does not initiate cyst formation," Journal of the American Society of Nephrology, vol. 21, no. 2, pp. 295-302, 2010.

[162] C. Liu, C. Lin, C. Gao, H. May-Simera, A. Swaroop, and T. Li, "Null and hypomorph Prickle1 alleles in mice phenocopy human Robinow syndrome and disrupt signaling downstream of Wnt5a," Biology Open, vol. 3, no. 9, pp. 861-870, 2014.

[163] S. S. Lienkamp, K. Liu, C. M. Karner et al., "Vertebrate kidney tubules elongate using a planar cell polarity-dependent, rosettebased mechanism of convergent extension," Nature Genetics, vol. 44, no. 12, pp. 1382-1387, 2012.

[164] J. T. Blankenship, S. T. Backovic, J. P. Sanny, O. Weitz, and J. A. Zallen, "Multicellular rosette formation links planar cell polarity to tissue morphogenesis," Developmental Cell, vol. 11, no. 4, pp. 459-470, 2006.

[165] O. Ossipova, K. Kim, B. B. Lake, K. Itoh, A. Ioannou, and S. Y. Sokol, "Role of Rabll in planar cell polarity and apical constriction during vertebrate neural tube closure," Nature Communications, vol. 5, article 3734, 2014.

[166] P. Montaldo, L. Montaldo, A. C. Iossa, M. Cennamo, E. Caredda, and R. del Gado, "Small renal size in newborns with spina bifida: possible causes," Clinical \& Experimental Nephrology, vol. 18, no. 1, pp. 120-123, 2014.

[167] D. Vaze, S. Mahalik, and K. L. N. Rao, "Novel association of VACTERL, neural tube defect and crossed renal ectopia-sonic hedgehog signaling: a point of coherence?" Congenital Anomalies, vol. 52, no. 4, pp. 211-215, 2012. 


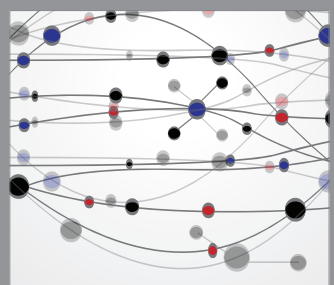

The Scientific World Journal
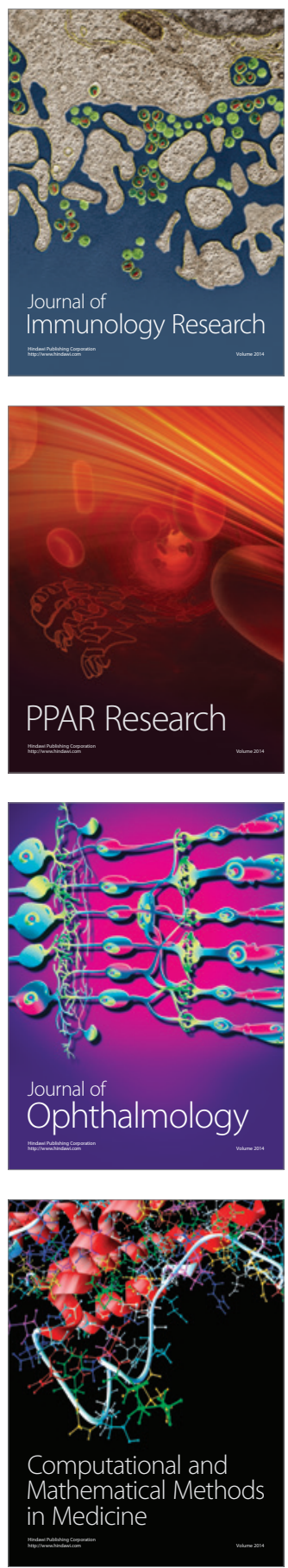

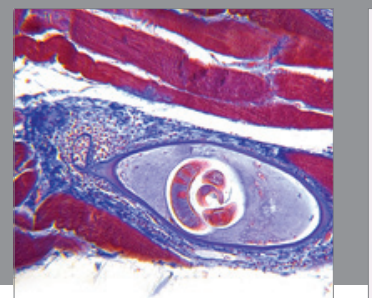

Gastroenterology

Research and Practice
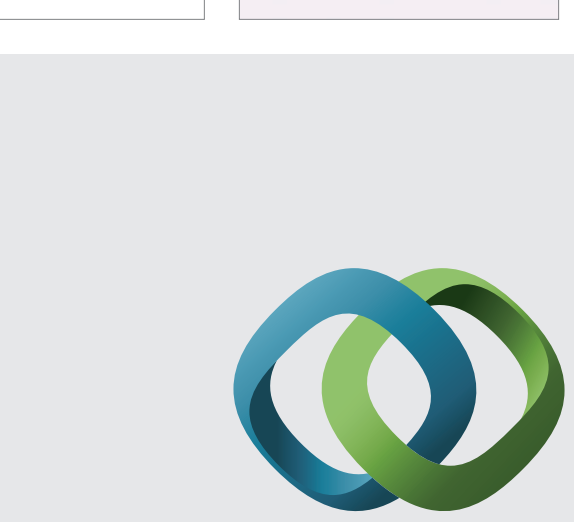

\section{Hindawi}

Submit your manuscripts at

http://www.hindawi.com
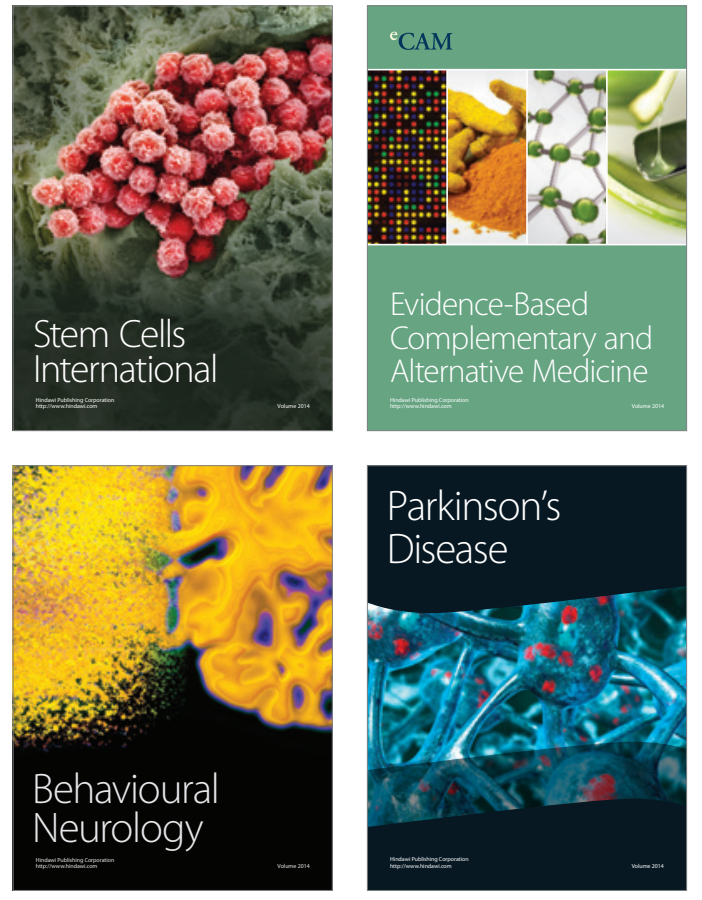
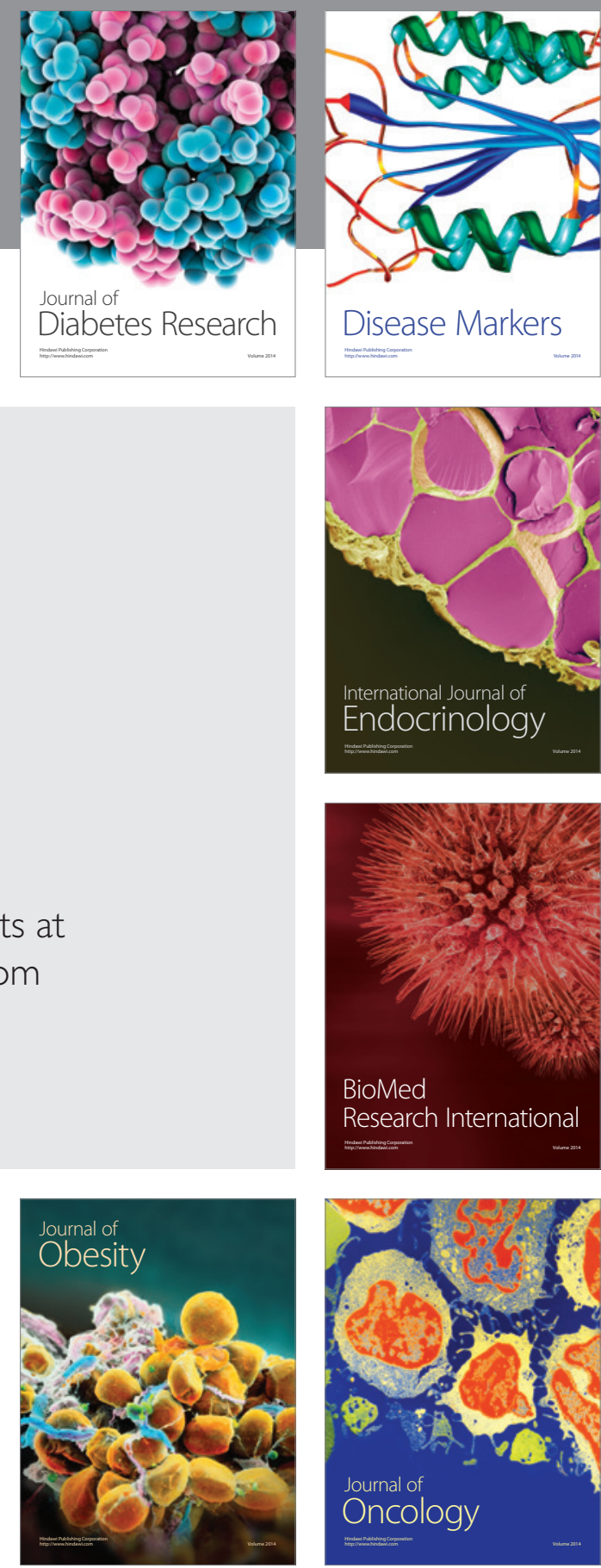

Disease Markers
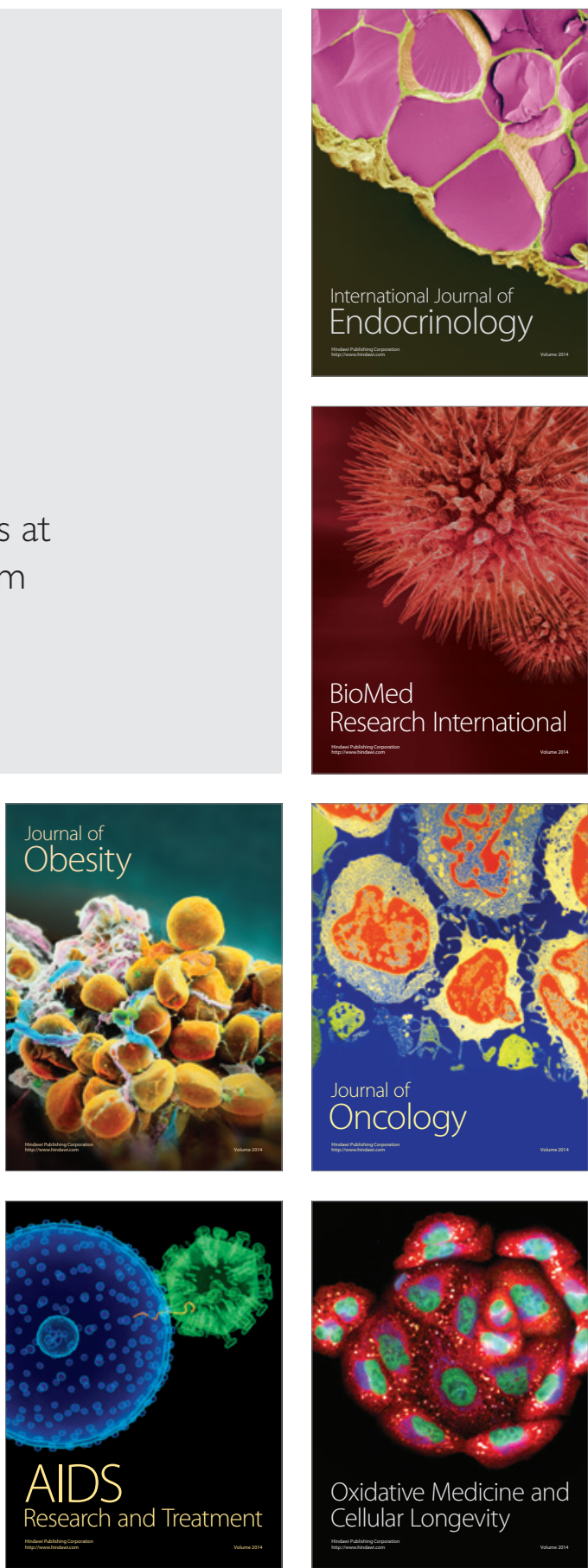